\title{
Solar radiative effects of a Saharan dust plume observed during SAMUM assuming spheroidal model particles
}

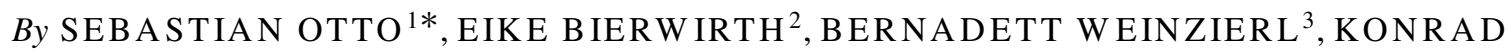 \\ KANDLER ${ }^{4}$, MICHAEL ESSELBORN ${ }^{3}$, MATTHIAS TESCHE ${ }^{5}$, ALEXANDER SCHLADITZ ${ }^{5}$, \\ MANFRED WENDISCH ${ }^{2}$ and THOMAS TRAUTM AN N ${ }^{1}, \quad{ }^{1}$ Institut für Methodik der Fernerkundung, \\ Deutsches Zentrum für Luft- und Raumfahrt (DLR) Oberpfaffenhofen, Münchner Straße 20, 82234 Wessling, \\ Germany; ${ }^{2}$ Institute for Atmospheric Physics, Johannes Gutenberg University Mainz, Becherweg 21, 55099 Mainz, \\ Germany; ${ }^{3}$ Institut für Physik der Atmosphäre, Deutsches Zentrum für Luft- und Raumfahrt (DLR) Oberpfaffenhofen, \\ Münchner Straße 20, 82234 Wessling, Germany; ${ }^{4}$ Institute of Applied Geosciences, Darmstadt University of \\ Technology, Schnittspahnstr. 9, 64287 Darmstadt, Germany; ${ }^{5}$ Leibniz Institute for Tropospheric Research (IfT), \\ Permoserstraße 15, 04318 Leipzig, Germany
}

(Manuscript received 12 February 2008; in final form 14 August 2008)

\begin{abstract}
The solar optical properties of Saharan mineral dust observed during the Saharan Mineral Dust Experiment (SAMUM) were explored based on measured size-number distributions and chemical composition. The size-resolved complex refractive index of the dust was derived with real parts of 1.51-1.55 and imaginary parts of $0.0008-0.006$ at $550 \mathrm{~nm}$ wavelength. At this spectral range a single scattering albedo $\omega_{o}$ and an asymmetry parameter $g$ of about 0.8 were derived. These values were largely determined by the presence of coarse particles. Backscatter coefficients and lidar ratios calculated with Mie theory (spherical particles) were not found to be in agreement with independently measured lidar data. Obviously the measured Saharan mineral dust particles were of non-spherical shape. With the help of these lidar and sun photometer measurements the particle shape as well as the spherical equivalence were estimated. It turned out that volume equivalent oblate spheroids with an effective axis ratio of 1:1.6 matched these data best. This aspect ratio was also confirmed by independent single particle analyses using a scanning electron microscope. In order to perform the non-spherical computations, a database of single particle optical properties was assembled for oblate and prolate spheroidal particles. These data were also the basis for simulating the non-sphericity effects on the dust optical properties: $\omega_{o}$ is influenced by up to a magnitude of only $1 \%$ and $g$ is diminished by up to $4 \%$ assuming volume equivalent oblate spheroids with an axis ratio of 1:1.6 instead of spheres. Changes in the extinction optical depth are within 3.5\%. Non-spherical particles affect the downwelling radiative transfer close to the bottom of the atmosphere, however, they significantly enhance the backscattering towards the top of the atmosphere: Compared to Mie theory the particle non-sphericity leads to forced cooling of the Earth-atmosphere system in the solar spectral range for both dust over ocean and desert.
\end{abstract}

\section{Introduction}

Saharan mineral dust is one of the most important aerosol components in the Earth's atmosphere. Its effects on the solar and thermal infrared radiation budget are still under discussion. How absorbing and scattering is the dust really? This is not an easy question to answer, since the spectral behaviour of such pro-

\footnotetext{
${ }^{*}$ Corresponding author.

e-mail: sebastian.otto@dlr.de

DOI: $10.1111 /$ j.1600-0889.2008.00389.x
}

cesses depends on a number of factors such as complex refractive index, typical dust size distributions, chemical composition, source region, particle mixing state as well as the particle shape. In this manner the microscopic properties of the dust particles have to be consideredas a starting point (Sokolik et al., 2001). Thus, extensive measurements were performed both at ground level as well as on aircraft during SAMUM which took place in May/June 2006. One of the main aims was to explore the micro-physical properties of the mineral dust, that is, the size distributions, the size-resolved mineralogical and chemical compositions and the size-resolved particle shape, which were then 
used to compute the macro-physical ensemble optical properties like the extinction and the backscatter coefficient as well as the lidar ratio in order to compare them to lidar observations collected during the SAMUM campaign. Since these optical properties of the dust result in certain effects on the radiation field, for continuative model validations spectral radiation measurements in the solar and thermal infrared range were also performed during SAMUM, too.

Information about the mineralogical and chemical composition as well as the mixing state of airborne particles are determining factors in understanding optical properties and radiative effects as discussed by, e.g., Sokolik and Toon (1999), Jacobson (2000), Myhre and Stordal (2001), Linke et al. (2006), Lafon et al. (2006), Koven and Fung (2006) and Balkanski et al. (2007). Therefore, analyses of individual particles are needed (see e.g. Falkovich et al., 2001) and were also performed during SAMUM. Particle size distributions also play a decisive role, e.g. demonstrated by Collins et al. (2000) in their closure studies, by Myhre and Stordal (2001) in their radiative forcing simulations and by Otto et al. (2007) who investigated the role of large dust particles. However, size distribution measurements can be challenging, since there is no standard method to obtain a distribution. Thus, several measurement techniques have to be exploited (Weinzierl et al., 2008) linked with possible errors (Reid et al., 2003). A further crucial error source in simulating optical properties and radiative effects of mineral dust is the uncertainty in the complex refractive index (Sokolik and Toon, 1999; Myhre and Stordal, 2001; Lafon et al., 2006; Mogili et al., 2007; Kahnert et al., 2007; Otto et al., 2007). Therefore, we will use the chemical composition of the airborne dust particles measured during SAMUM to compute size-resolved spectral complex refractive indices based on a large number of spectral optical constants of major constituents of mineral dust from the literature.

The large particle fraction of mineral dust has a strong impact on the ensemble optical properties and atmospheric radiative effects (d'Almeida et al., 1991; von Hoyningen-Huene and Posse, 1997; Tegen and Lacis, 1996; Markowicz et al., 2003; Kahnert and Kylling, 2004; Otto et al., 2007). However, the size and concentration measurement of large particles is complicated and influenced by measurement uncertainties (Reid et al., 2003) and technical limitations (Haywood et al., 2003). Their importance also becomes obvious by the fact that remote sensing techniques (Wendisch and von Hoyningen-Huene, 1994; Kaufman et al., 2001) and retrieval algorithms as used within the scope of AERONET (Dubovik et al., 2002a, 2006) yield optical properties and size distribution information for mineral dust ensembles, different to those measured in-situ (Formenti et al., 2000; Schmid et al., 2000) and modelling studies (Cattrall et al., 2003; Balkanski et al., 2007). Note that this discrepancy is not only due to the influence of large particles. It is also dependent on the mineralogical constitution of the ensemble, the uncertainties in the complex refractive index and the non-sphericity of the particles as well as the environmental conditions of the atmosphere, since for example satellite retrieval methods observe the radiation transported upward through an entire atmospheric column.

In simulations of the optical properties and the radiative effects of aerosol populations spherical model particles are usually assumed because optics for spheres can be calculated easily. The errors linked with these assumptions are discussed, e.g., by Kahnert et al. (2005) and Kahnert et al. (2007) who compared Mie calculated phase functions of mineral aerosol samples (Volten et al., 2001) to laboratory-measured ones. The authors found that the spherical particle approximation 'is probably among the major sources of error in quantifying the climate forcing effect of mineral aerosols' and stated that certain spheroidal shape parameterisations can substantially diminish the differences to these measured data.

Desert dust particles are usually of inhomogeneous structure having non-spherical as well as complex shapes. To simulate their scattering and absorbing properties time-consuming single scattering methods have to be exploited. However, the use of spheroidal particle shapes as a first step already requires enormous computational effort. Nevertheless, Pilinis and Li (1998) estimated the climate forcing of prolate spheroidal model particles with an aspect ratio (AR) of 1.9 and found that this assumption can result in a forcing which is different by a factor of 3 compared to spherical particles. They reported that the shape is important for the upwelling scattered radiation, 'especially for small solar zenith angles and super-micron-sized particles', and that the upward transported radiaition is underestimated when adopting spherical particles. This is in accordance with Yang et al. (2007) who estimated the influence of prolate spheroidal model particles (AR 1.7) on the radiation field and stated that the non-sphericity affects the short-wave radiative transfer significantly, but would have no impact in the long-wave. Schulz et al. (1999) investigated the effect of the aspect ratio on the scattering by prolate spheroids for ARs ranging from 1.1 to 15 . They found that the single scattering albedo $\omega_{o}$ as well as the asymmetry parameter $g$ of the ensemble are strongly affected by the variation of these different ARs and are near-linear functions of an effective AR. On the other hand, when varying the AR moderately up to values of 2.4 the ensemble-averaged $\omega_{o}$ and $g$ change only weakly (Nousiainen and Vermeulen, 2003; Kahnert and Kylling, 2004; Kahnert et al., 2005; Yang et al., 2007), for both prolate and oblate model particles (Mishchenko et al., 1997).

However, $g$ is an integrated quantity of the scattering phase function $P$. Although the AR has an effect on the shape of $P$ versus the scattering angle $\theta_{s}$ as the previous cited works demonstrate, $g$ is less strongly affected. Thus, radiative transfer codes, which use the Legendre expansion coefficients of $P$ instead of $g$, show significantly different scattering properties when applying spheroidal model particles leading to big impacts on simulated radiation fields (Kahnert and Kylling, 2004; Kahnert et al., 2005) which is important for remote sensing 
(Wang et al., 2003). Such AR effects on $P$ also influence the modelled extinction-to-backscatter ratio (lidar ratio) with large spherical-non-spherical differences (Mishchenko et al., 1997) and 'should be explicitly taken into account' in comparing simulations to lidar measurements of mineral dust.

Therefore, we consider size distributions of airborne dust particles, their chemical and mineralogical composition as well as ARs measured during SAMUM to compute the solar radiation field assuming spherical as well as non-spherical particles (randomly oriented homogeneous spheroids). The simulated radiation quantities are then compared to measured lidar, sun photometer and spectral irradiance data in order to achieve a radiative closure. Section 2 gives an overview of the measurements during SAMUM that were important for this paper. Section 3 reports on the radiative transfer model and Section 4 on the database of the single particle optical properties of spheroids to compute the spherical as well as non-spherical spectral optical properties of the mineral dust ensembles observed during SAMUM. These are discussed in Section 5, in which also the solar radiative effects of the non-spherical dust particles are quantified. Section 6 presents their atmospheric radiative effects.

\section{SAMUM measurements}

The following measurement data were most important for the present paper: (1) Size-number distributions of the airborne dust particles as a basis to simulate extinction, (2) single particle analyses of the degree of the non-sphericity of the particles as well as their chemical composition as a function of the particle size, which we have used to derive the spectral and size-resolved complex refractive index of the dust. (3) The spectral surface albedo and (4) the vertical structure of the atmosphere (e.g. pressure, temperature and humidity). These quantities (1)-(4) are needed as input to our radiative transfer model for simulating the optical properties and the radiation field of a dusty atmosphere at solar wavelengths. For the validation of such computations (5) spectral downwelling and upwelling energy flux densities (irradiances) as well as actinic flux densities were measured during SAMUM at the ground and on the aircraft to achieve radiative closure. (6) Various multi-wavelength lidar observations were performed in order to give information about the non-sphericity of the dust particles.

The SAMUM campaign took place in May/June 2006 in Morocco, see Fig. 1, around Zagora (ZGA, $\sim 730 \mathrm{~m}$ above sea level [a.s.1.]), Tinfou ( $\sim 20 \mathrm{~m}$ a.s.1.) and Ouarzazate (OZT, $\sim 1150 \mathrm{~m}$ a.s.l.). A more detailed overview of SAMUM is given by Heintzenberg (2008). In the following we refer to the campaign day 19 May 2006, declared as one of SAMUM's golden days, for which most of the required data were available.

\subsection{Radiation and surface albedo}

During SAMUM ground-based radiation measurements were carried out at OZT almost continuously, and aircraft-based data

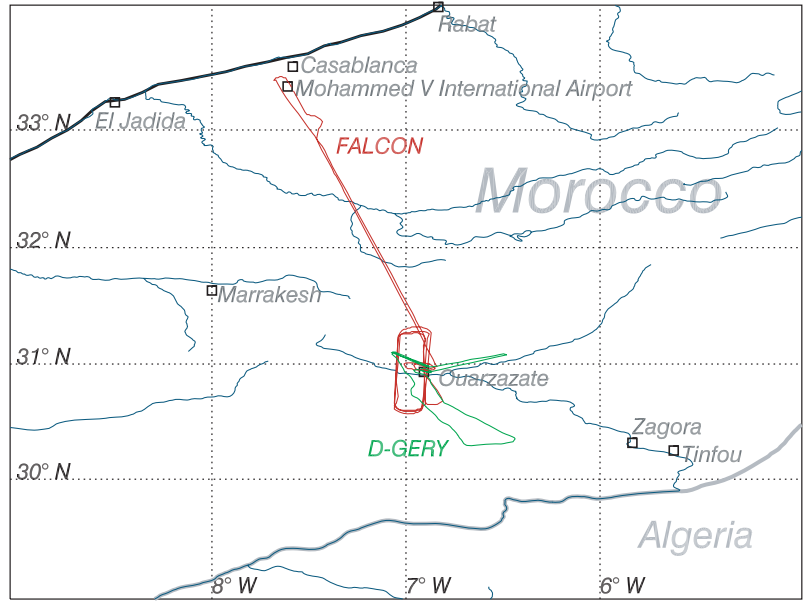

Fig. 1. Map of Morocco with the location of the SAMUM ground sites Ouarzazate, Zagora and Tinfou. The flight tracks of the FALCON and D-GERY on 19 May 2006, during SAMUM are drawn red and green.

were collected on the Partenavia P68 aircraft (D-GERY) covering different spectral ranges, that is, spectral downwelling and upwelling energy flux densities/actinic flux densities at the aircraft (from 290 to $2200 \mathrm{~nm}$ ) and the downward ones at ground (from 280 to $1050 \mathrm{~nm}$ ), which were measured by Bierwirth et al. (2008).

Various flight legs were flown at relatively low altitudes in order to retrieve spectral surface albedo information from the aircraft-based radiation measurements along the flight tracks. To extrapolate these airborne albedo observations to the ground Bierwirth et al. (2008) applied a technique that was developed by Wendisch et al. (2004). Since the surface albedo is one of the most important factors which affect the radiation transport through the atmosphere, such data can demonstrate the smallscale spatial variability of the Earth's surface properties and are used as lower boundary condition in our radiative transfer simulations.

Using both measurements, radiation and surface albedo, the present paper tries to achieve a radiative closure of a mineral dust layer observed over the Sahara desert.

\subsection{Dust size distributions}

A second research aircraft, the DLR FALCON 20-E, measured, among other parameters, the size distributions of the airborne Saharan mineral dust particles as well as the particle number concentrations of the accumulation mode. These distributions were also essential for the present work, since our goal was to start with the micro-physical properties, that is, the sized dust particles considering their chemical composition and common shapes.

On the campaign day 19 May 2006, the observed mineral dust plume was vertically well mixed (Weinzierl et al., 2008). Two 


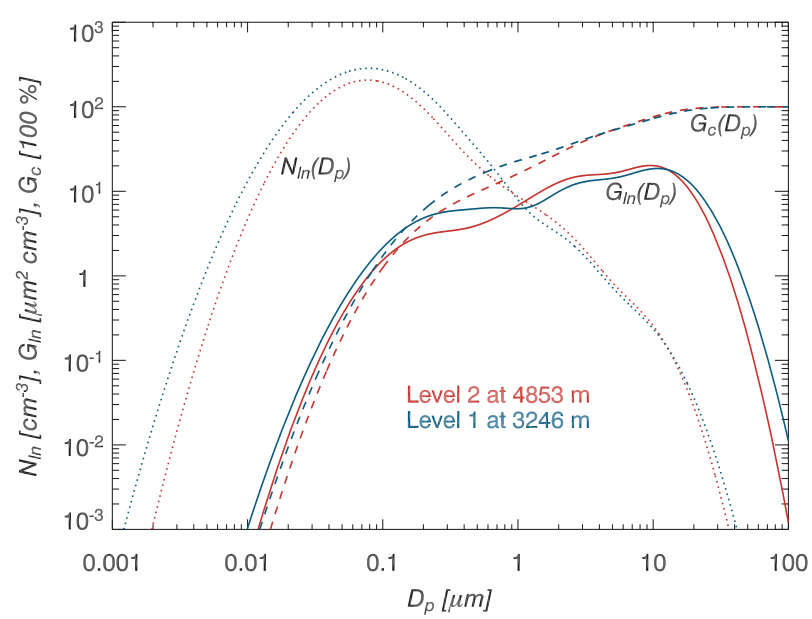

Fig. 2. Number concentration size distributions $N_{\ln }\left(D_{p}\right)$ log-normally fitted to aircraft-based measurements on 19 May 2006, at two altitudes (ambient conditions). $G_{\ln }\left(D_{p}\right)$ and $G_{c}\left(D_{p}\right)$ after the eqs (1)-(3) in the main text.

mean size-number distributions of the lifted dust were measured at constant flight levels at $3246 \mathrm{~m}$ and $4853 \mathrm{~m}$ a.s.l. For more detailed information about the set of the applied measurement instruments see Weinzierl et al. (2008). From log-normal fits to these particle data the modal parameters $N_{i}$ (mode number concentration $\left.\left[\mathrm{cm}^{-3}\right]\right), \sigma_{i}$ (mode standard deviation [1]) and $D_{p, i}$ (mode median diameter $[\mu \mathrm{m}]$ ) were derived to determine four-modal number concentration size distributions defined by (Weinzierl et al., 2008)

$N_{\ln }\left(D_{p}\right)=\sum_{i=1}^{4} \frac{N_{i}}{\sqrt{2 \pi} \ln \sigma_{i}} \exp \left[-\frac{\left(\ln D_{p}-\ln D_{p, i}\right)^{2}}{2 \ln ^{2} \sigma_{i}}\right]$.

These distributions are shown in Fig. 2. The log-normal expressions $N\left(D_{p}\right)=\frac{1}{D_{p}} N_{\ln }\left(D_{p}\right)$ were used in the present work to integrate the single particle optical properties. The 'size' $D_{p}$ is treated as a certain size equivalent parameter, e.g. the volume equivalent diameter, which determines the volume, the surface and the cross-section of the non-spherical (spheroidal) model particles in a size bin. $D_{p}$ ranges always from 0.01 to $50 \mu \mathrm{m}$.

To demonstrate the potential contribution of the differently sized particles to the optical behaviour of the entire ensemble we calculated cross-section weighted distributions (now assuming spheres as particle shape) by

$G_{\ln }\left(D_{p}\right)=\frac{\pi}{4} D_{p}^{2} N_{\ln }\left(D_{p}\right):=D_{p} G\left(D_{p}\right)$

where $G\left(D_{p}\right)$ is the log-normal cross-section concentration size distribution (integration in terms of $D_{p}$ ). With the help of $G$ cumulative distributions

$G_{c}\left(D_{p}\right)=\frac{1}{G_{c}\left(D_{p}^{\max }\right)} \int_{\left(D_{p}^{\min }, D_{p}\right)} G(s) d s \quad \forall D_{p} \leq D_{p}^{\max }$

were derived. $G_{c}$ demonstrates (Fig. 2) that particles larger than $1 \mu \mathrm{m}$ potentially dominate the optical properties of a particle ensemble by up to $80 \%$ due to their larger geometric crosssection (d'Almeida et al., 1991; Tegen and Lacis, 1996; von Hoyningen-Huene and Posse, 1997; Kahnert and Kylling, 2004; Otto et al., 2007). Of course, these depend also on the optical efficiencies and particle number concentrations, which are functions of the refractive index or/and the particle size. We also calculated $G_{\ln }$ and $G_{c}$ for volume equivalent oblate spheroids with an aspect ratio of 1:1.6. The respective curves were similar to the case of spherical particles leading to qualitatively the same conclusion with respect to the importance of the large particles.

\subsection{Environmental conditions}

Two radiosondes were launched on 19 May 2006, at OZT, the first one in the morning at 10:38 UTC and the second one in the evening at 19:59 UTC (Ansmann et al., 2008; Tesche et al., 2008). Figure 3 shows the respective profiles of pressure, temperature and relative humidity whereby the latter was used to derive the volume mixing ratio of water vapour. The figure also presents the data measured onboard the FALCON during the flight legs on that day. The aircraft-based profiles confirm the data from the radiosonde in the morning. In the evening the relative humidity is strongly increased above an altitude of $5 \mathrm{~km}$. Moreover, comparing these humidity data to the tropical standard profile (Anderson et al., 1986) it is obvious that the lower atmosphere over desert is rather drier.

For the radiative transfer simulations later in this paper the FALCON profile data were taken to determine the lowest part of the model atmosphere. Above the maximum altitude of $9.3 \mathrm{~km}$ that could be reached by the FALCON, the model profiles ('USED PROFILE') follow the radiosonde data up to $24 \mathrm{~km}$ and then the tropical standard curves.

The importance of the environmental conditions, such as the water-vapour profile, for radiative transfer simulations of in-situ measured radiation is reported by Collins et al. (2006) who discussed the influence of different spectroscopic data, to describe gas absorption by line parameters as also used in the present work, on the radiative heating of the Earth's climate system. If an absorbing atmosphere also contains multiple scattering aerosol as Saharan mineral dust, the use of in-situ measured environmental data is important all the more, since both extinction processes interact non-linearly.

\subsection{Lidar instruments}

The high spectral resolution lidar (HSRL) developed by the Institute of Atmospheric Physics at DLR Oberpfaffenhofen was installed onboard the FALCON (Esselborn et al., 2008a). This nadir-looking instrument allows to investigate dust plumes during the flight to give an in-situ impression to the field scientists on the vertical structure and mass content of present dust layers. This is important for their decisions for local aircraft-based measurements of dust size distributions and allows one to analyse the number concentrations of the particles as well as their optical 

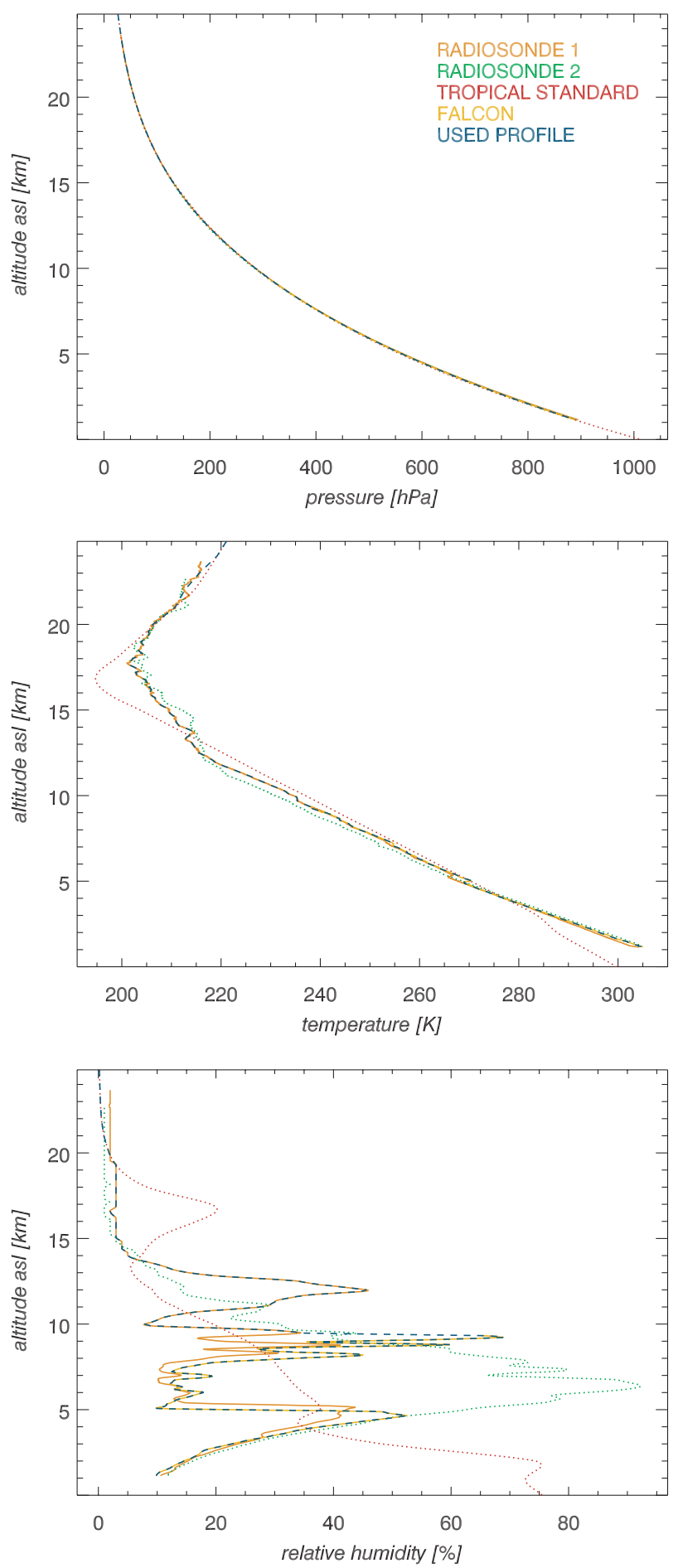

Fig. 3. Measured pressure, temperature and relative humidity on 19 May 2006, at OZT at 10:38 UTC (Radiosonde 1) and 19:59 UTC (Radiosonde 2) as well as onboard the FALCON compared to tropical standard profiles. impact of more or less the same plume (Petzold et al., 2008). Thereby, the HSRL measures the backscatter coefficient

$k_{s, \text { back }}\left(x_{3}, \lambda\right):=\frac{1}{4 \pi} k_{s}\left(x_{3}, \lambda\right) P\left(x_{3}, \lambda, \theta_{s}=180^{\circ}\right)$

by time-averaging the backscattered lidar signals (Esselborn et al., 2008b). Here $P$ is the scattering phase function, $\theta_{s}$ the scattering angle and $k_{s}$ the scattering coefficent as a function of the altitude $x_{3}$ and the wavelength $\lambda$. Using $k_{s, \text { back }}$ and the extinction coefficent $k_{e}\left(x_{3}, \lambda\right)$ the lidar ratio can be calculated which is defined by

$L(\lambda):=\frac{k_{e}\left(x_{3}, \lambda\right)}{k_{s, \text { back }}\left(x_{3}, \lambda\right)} \equiv \frac{4 \pi}{\omega_{o}\left(x_{3}, \lambda\right) P\left(x_{3}, \lambda, \theta_{s}=180^{\circ}\right)}$

with the single scattering albedo $\omega_{o}=\frac{k_{s}}{k_{e}}$. In the present work the HSRL data at $532 \mathrm{~nm}$ were used for comparisons to the simulated optical properties. Note that the profile information for the lower part of the atmosphere provided by the lidar depends on the ground elevation and the time interval to be averaged. In the case of SAMUM's 19 May the HSRL could not determine the optical properties below about $900 \mathrm{~m}$ above ground level (a.g.1.).

A second lidar was installed at the airport of OZT. This was the six-wavelength aerosol lidar BERTHA (backscatter extinction lidar-ratio temperature humidity profiling apparatus) of the Leibniz Institute for Tropospheric Research (Althausen et al., 2000) which measured at certain wavelengths between 355 and $1064 \mathrm{~nm}$. The BERTHA data of $k_{e}$ and $L$ at 355 and $532 \mathrm{~nm}$, making use of the Raman technique (Tesche et al., 2008), were taken for validation of the modelled profiles. Note that the overlap of the laser beams of BERTHA prohibits the measurement below about $200 \mathrm{~m}$ a.g.l.

\subsection{Chemical composition and complex refractive index}

Mineral dust particles mainly consist of the major mineral groups silicates, quartz, carbonates (calcite), sulfates and iron-rich materials (Sokolik and Toon, 1999; Falkovich et al., 2001; Perrone et al., 2004; Koven and Fung, 2006; Linke et al., 2006; Lafon et al., 2006; Balkanski et al., 2007). During SAMUM the volume fractions of these constituents were estimated by Kandler et al. (2008) via comprehensive single particle analyses (SPAs) using a scanning electron microscope (SEM) with an attached energy-dispersive X-ray analysis system for particles at ground (measured at Tinfou close to Zagora) and airborne ones. About 74000 particles were analysed: 45000 (Tinfou), 17000 (D-GERY) and 12000 (FALCON). The SPA provides size information, the morphology and element-chemical composition of the detected particles.

Figure 4 shows the results of the SPA for the campaign day 19 May. The chemical composition with regard to volume portions is dominated by silicates but small/large particles can also contain a significant fraction of sulfates/quartz, and although 

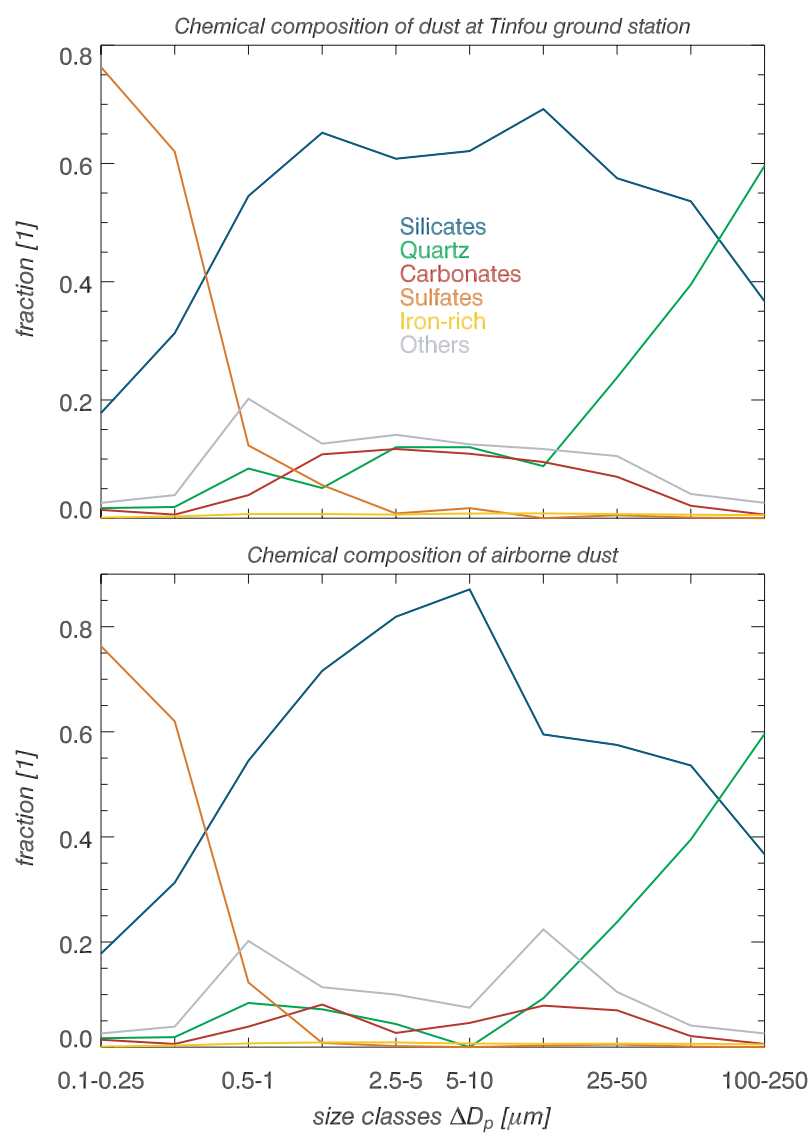

Fig. 4. Volume fraction of the main constituent groups of Saharan mineral dust as function of particle size exploited by single particle analyses on 19 May, 2006, at ground (top panel) and on aircraft (bottom panel). The data of the airborne dust were limited by particle sizes of about $25 \mu \mathrm{m}$. For larger particles the data at Tinfou level were taken.

the portion of iron-rich material is low compared to silicate, it can strongly contribute to the refractive index of dust mixtures, since its imaginary part is by orders of magnitude larger than the values for the remaining constituents (Fig. 5). Note that the SPAs can provide even more detailed information about individual species which were contained in the particle samples but had to be combined in component classes due to the fact that for most of the individual species no refractive index data were available over the entire spectral range. So we defined five component classes and determined their mean optical constants for our radiation simulations. In this context we emphasise the need for more comprehensive refractive index information, both for further species but mainly with full spectral cover. The following constituents were assumed in the mineral classes mentioned before:

- Silicates: illite, kaolinite, chlorite

- Quartz: quartz

- Carbonates: calcite

- Sulfates: sulfuric acid, ammonium sulfate, gypsum

- Iron-rich: wüstite, hematite, magnetite.
Table 1. References for the complex refractive indices of major constituents of mineral dust and dust ensembles

\begin{tabular}{lc}
\hline Constituents & References \\
\hline Silicates & \\
Illite & Egan and Hilgeman (1979) \\
& Glotch et al. (2007) \\
Kaolinite & Egan and Hilgeman (1979) \\
& Roush et al. (1991) \\
& Arakawa et al. (1997) \\
& Glotch et al. (2007) \\
Chlorite & Mooney and Knacke (1985) \\
Quartz & Popova et al. (1972) \\
& Ivlev and Popova (1972) \\
& Steyer et al. (1974) \\
& Shettle and Fenn (1979) \\
& Philipp (1985) \\
& Zukic et al. (1990) \\
& Henning and Mutschke (1997)
\end{tabular}

Carbonates

Calcite

Gypsum

\section{Iron-rich}

Wüstite

Hematite

Magnetite

\author{
Ivlev and Popova (1972) \\ Querry et al. (1978) \\ Long et al. (1993) \\ Tropf (1998) \\ Jarzembski et al. (2003) \\ Palmer and Williams (1975) \\ Volz (1973) \\ Toon et al. (1976) \\ Shettle and Fenn (1979) \\ Jarzembski et al. (2003) \\ Ivlev and Popova (1972) \\ Aronson et al. (1983) \\ Long et al. (1993)
}

Henning et al. (1995)

Shettle and Fenn (1979)

Hsu and Matijevic (1985)

Querry (1987)

Gillespie and Lindberg (1992)

Bedidi and Cervelle (1993)

Marra et al. (2005)

Glotch et al. (2007)

Gillespie and Lindberg (1992)
Note: References of ensemble data

Volz (1972, 1973), Lindberg and Laude (1974),

Lindberg (1975), Lindberg and Gillespie (1977),

Patterson et al. (1977), Carlson and Caverly (1977),

Shettle and Fenn (1979), Carlson and Benjamin (1980),

Levin et al. (1980), Ivlev and Andreev (1986),

Zuev and Krekov (1986), Fouquart et al. (1987),

Sokolik et al. (1993) and Hess et al. (1998) 


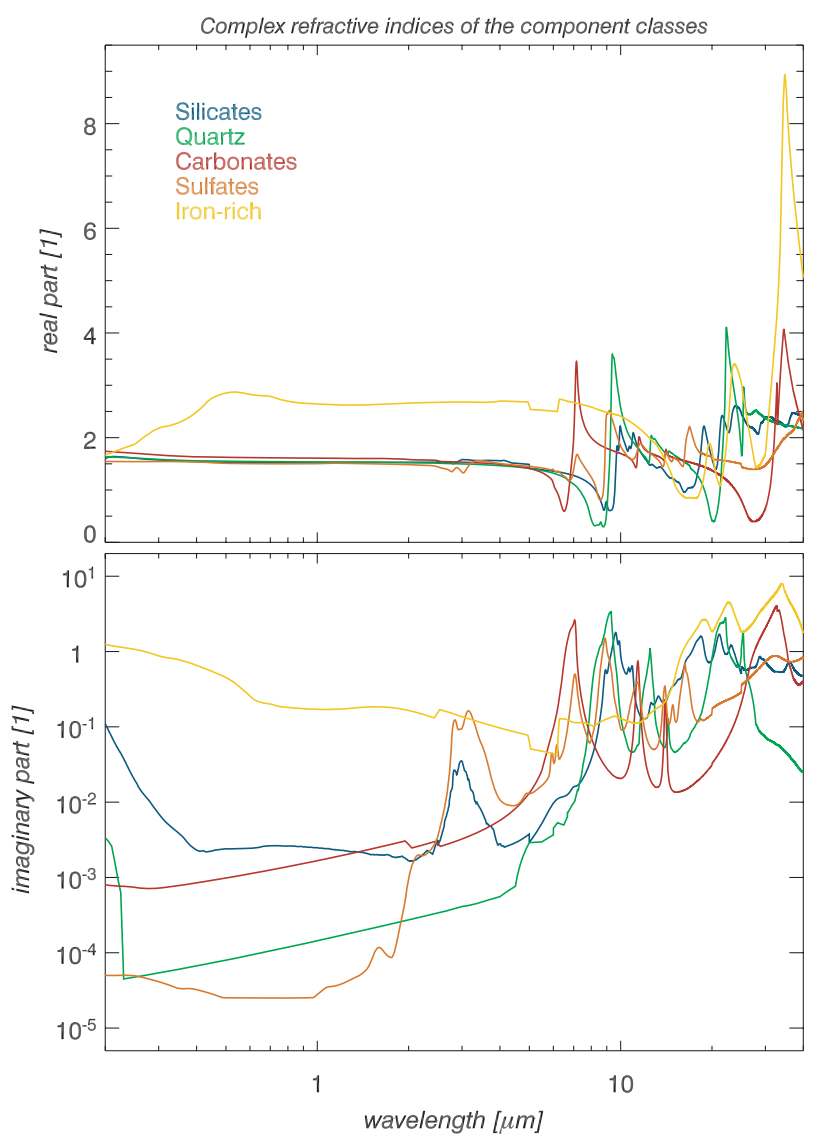

Fig. 5. Spectral complex refractive indices of the following material groups that are representative for mineral dust mixtures: silicates, quartz, carbonates, sulphates and iron-rich materials. The curves were calculated using moving averages of spectral literature data cited in Table 1. For anisotropic materials ordinary complex refractive index data were taken.

Table 1 lists a large number of literature data which were exploited to calculate the mean complex refractive indices of the five mineral classes covering a large spectral range from $200 \mathrm{~nm}$ to $40 \mu \mathrm{m}$. It turned out that most data were available for the longwave range, not in the short-wave. That was critical, since the optical constants in the short-wave are the determining factors for most of the extinction processes in the solar region. The silicate class was especially problematic with the main constituents being orthoclase, illite, albite, kaolinite and chlorite. Either no data of short-wave optical constants were available, the spectral variabilities in the literature data were critical factors or the literature constants seemed to be questionable.

Figure 5 depicts the spectral dependence of the real and imaginary parts of the complex refractive indices of the five relevant material groups. Using these data as well as a simple volume mixing rule the complex refractive indices, representative for the particle size classes presented in Fig. 4, were computed for Saharan mineral dust collected at ground level and on the air-

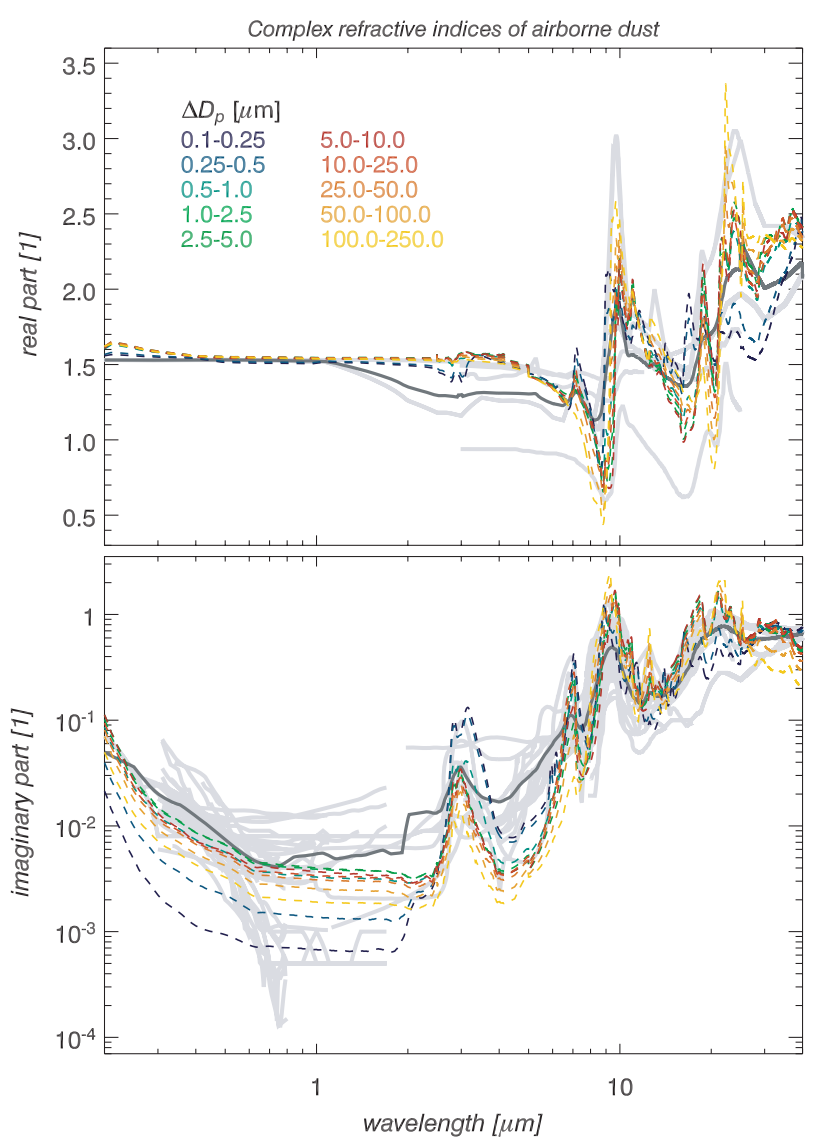

Fig. 6. Mean spectral complex refractive indices for the measured airborne Saharan dust (coloured curves) as function of the particle size class (the ground-based data are very similar). The light grey curves represent the refractive indices of the ensemble data cited in Table 1, and using the latter ones the dark grey curves was computed via moving averages.

craft by Kandler et al. (2008) during SAMUM. The resulting curves are shown in Fig. 6 and demonstrate significant variability of the optical constants over the particle size and wavelength ranges (Lindberg and Gillespie, 1977; Volz, 1983). Note that the smallest particles, less important for optical effects compared to larger ones, exhibit low imaginary parts in the short-wave, too.

In Fig. 6 the ensemble refractive index data (light grey) found in the literature (Table 1) are plotted for comparison to the derived ones (coloured) using the measured component data. The latter are within the uncertainty of the literature data in most of the spectral regions. Especially in the short-wave small differences to the literature mean complex refractive index (dark grey) occur showing similar spectral trends.

Figure 7 presents the mean complex refractive indices of the measured airborne dust of Fig. 6 as function of the particle size for certain short-wave wavelengths. It turns out that the real part around $550 \mathrm{~nm}$ varies only slightly with particle size from $\sim 1.54$ to maximum 1.552 for particle diameters larger than 


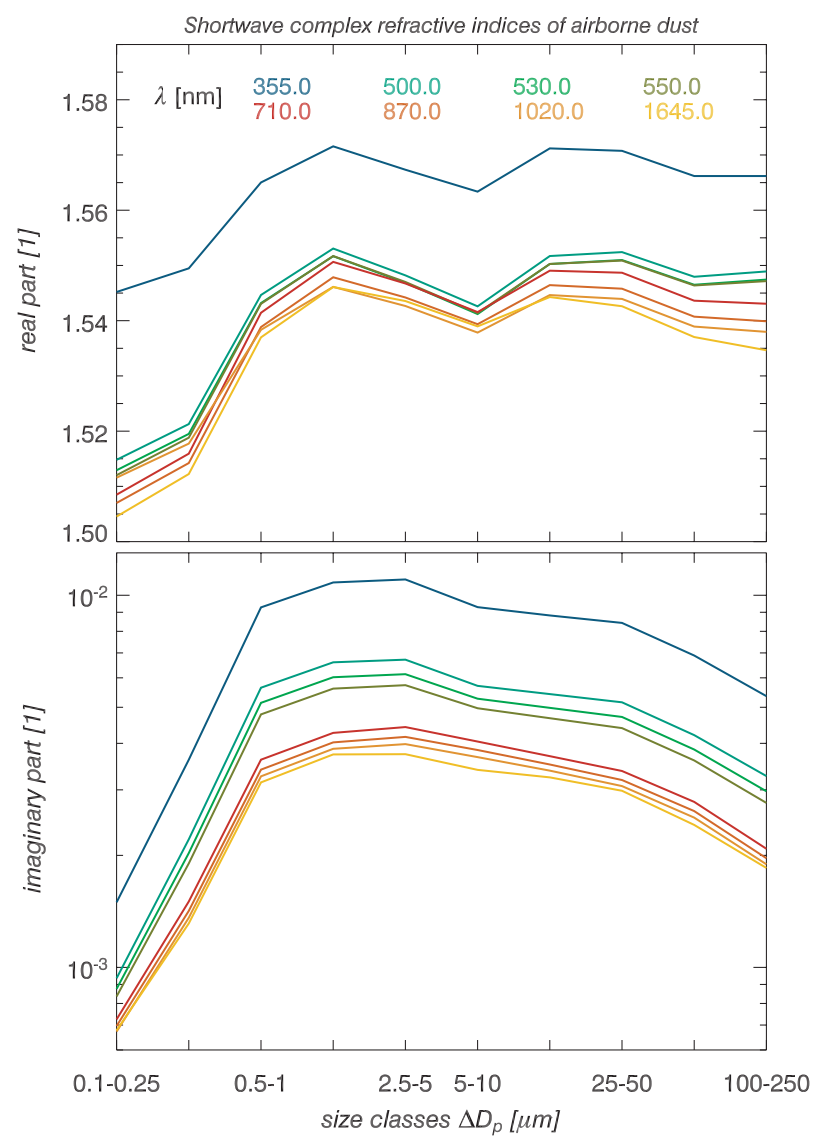

Fig. 7. Mean complex refractive indices of the measured airborne Saharan mineral dust at short-wave wavelengths as function of particle size.

$\sim 1 \mu \mathrm{m}$. For smaller particles it drops down to minimum $\sim 1.512$. Kandler et al. (2008) reported a similar behaviour for dust measured at Tinfou ground station based on SPA and found values of 1.55-1.57 around this wavelength and for these particle ranges. Petzold et al. (2008) confirmed these values presenting estimates of $1.561 \pm 0.003$ using airborne particle data. The same variation with size holds for the imaginary part: For the radiatively effective particles with diameters from $\sim 1$ to $30 \mu \mathrm{m}$ (Fig. 2 ) it is relatively constant around $550 \mathrm{~nm}$ with values from $\sim 0.004$ to maximum 0.0057 . For smaller particles we derived values down to the minimum of 0.00084 due to the larger fraction of sulfates (Fig. 4). Petzold et al. (2008) found $0.0042 \pm 0.0007$ at $550 \mathrm{~nm}$ and Kandler et al. (2008) presented 0.0028 for smaller as well as 0.0037 for larger particles at $530 \mathrm{~nm}$. At $537 \mathrm{~nm}$ Schladitz et al. (2008) estimated $0.0042 \pm 0.0017$ on 17-21 May for dust samples from Tinfou and Müller et al. (2008) derived 0.0020.005 at $550 \mathrm{~nm}$ on 19-20 May depending on the correction of minute amounts of soot observed at the same site. All these cited complex refractive index data for 19 May during SAMUM, obtained using various measurement techniques, demonstrate that the imaginary part of the observed Saharan mineral dust was not lower than $\sim 0.002$ at $550 \mathrm{~nm}$. In this context we note the cut-off problem for measuring particles and estimating refractive indices for dust whose coarse mode fraction is not present in the analyses. Recalculations of the optical properties are then only representative for the smaller particles of a dust ensemble (Haywood et al., 2003; Osborne et al., 2008). However, the size distribution measurements at Tinfou ground station (Kandler et al., 2008) as well as on aircraft (Weinzierl et al., 2008) demonstrated the presence of coarse particles within the entire dust plume.

The complex refractive indices of Fig. 6 were used in our calculations of the spherical as well as the spheroidal optical properties of the Saharan mineral dust when integrating over the measured size distributions and were also used as input into the radiative transfer simulations later in this paper.

\subsection{Non-spherical particles and their shapes}

SPAs were performed to investigate typical shapes of the sampled dust particles which showed both regular and bizarre shapes in the SEM. Unfortunately, this method merely enables one to determine the cross-sections of the analysed particles. It turned out that the assumption of an elliptical cross-section, expressed by the ratio of the half axes of an adopted ellipse (aspect ratio, AR), suited the observations well (Kandler et al., 2008). Therefore, the sampled dust particles were approximated by spheroids and fitted log-normal distribution functions for their ARs were derived. The analyses demonstrated that the ARs of submicron particles were distributed rather narrowly with typical medians around 1.3 but broader for supermicron particles leading to medians of about 1.6 (Kandler et al., 2008).

The AR distributions of the airborne Saharan dust particles were determined as function of particle size class as well as composition and are available for different altitude ranges. Although our radiative transfer model is able to deal with such measured or theoretical (Mishchenko et al., 1997; Nousiainen et al., 2006) distributions, we assumed constant ARs for all non-spherical model particles considering them as effective ARs instead of shape mixtures (Mishchenko and Travis, 1994b) to minimise the computational effort.

\section{Radiative transfer model package}

All radiative transfer simulations were performed using the model package TRAVIS (Toolbox for Radiative transfer Applications from Visible to Infrared wavelengthS). Its basic features were described in more detail by Otto et al. (2007). The following issues are new:

- Implementation of DISORT2 (Stamnes et al., 1988, 2000) as an improved multiple-stream radiative transfer solver. 
- Implementation of an analytical delta-four-stream as well as several analytical delta-two-stream solvers applicable to inhomogeneously layered absorbing and scattering media considering two source terms of radiation over the entire spectral range: the extraterrestrial solar source as well as Planckian emission.

- The gas absorption is calculated using line parameters of the main absorbing gases given by the high-resolution transmission molecular absorption database (HITRAN; see http://cfawww.harvard.edu/HITRAN/) of 2004 (Rothman et al., 2005). In addition to the interval cut-off a line cut-off was installed. This avoids that the spectral grid of the model has to be adjusted to the continuum absorption spectrum of water vapour. Thus, the spectral resolution can be chosen arbitrarily from line-by-line to broadband applications considering certain cut-offs.

- The UV absorption tool was revised by the implementation of further cross-section data: $\mathrm{O}_{3}$ (Bass and Paur, 1981; Molina and Molina, 1986; Burrows et al., 1999; Bogumil et al., 2000; Voigt et al., 2001), $\mathrm{NO}_{2}$ (Burrows et al., 1998; Vandaele et al., 1998; Bogumil et al., 2000; Voigt et al., 2002), $\mathrm{NO}_{3}$ (Orphal et al., 2003), $\mathrm{SO}_{2}$ (Bogumil et al., 2000; Freeman et al., 1984), $\mathrm{N}_{2} \mathrm{O}$ (Yoshino et al., 1984), $\mathrm{H}_{2} \mathrm{CO}$ (Cantrell et al., 1990), BrO (Wilmouth et al., 1999; Fleischmann et al., 2004), OClO (Kromminga et al., 2003).

- The model can now be driven in the wavelength as well as in the wavenumber space for short-wave and long-wave computations.

- Parallelisation of the model for saving computing time and memory. This makes the model applicable for more complex situations, e.g. of a high number of model layers, streams or Legendre polynomials of the scattering phase function, and allows one to compute non-spherical aerosol optical properties in an appropriate time span with access to a database of spheroidal single particle optical properties when integrating over an assumed size distribution. Moreover, for each particle a distribution of the aspect ratio (AR) can be adopted for averaging over certain particle shapes (oblate and/or prolate spheroids).

Vertical resolutions of the model atmospheres of $\Delta z=25 \mathrm{~m}$ and $100 \mathrm{~m}$ were used between the bottom of the atmosphere (BOA) and $20 \mathrm{~km}$ altitude for the radiative transfer simulations over desert and ocean. Above the $20 \mathrm{~km}$ a $\Delta z=1 \mathrm{~km}$ was assumed in both cases up to a maximum altitude of $70 \mathrm{~km}$ meaning 489 and 250 homogeneous layers, respectively. The Air Force Geophysics Laboratory tropical model following Anderson et al. (1986) was used to define the model atmosphere where, however, in the lowest altitude range the profile measurements of the meteorological quantities, see Section 2.3, were taken instead.

Since the model simulations of the transported radiation are compared to measured solar spectra, the spectral grid of the model was adjusted to their wavelength range from $318 \mathrm{~nm}$ to $2167 \mathrm{~nm}$ with a resolution of $1 \mathrm{~nm}$. This spectral region was also considered for the calculations of the solar atmospheric radiative effects (AREs) at BOA, directly above the dust layer as well as at the top of the atmosphere (TOA).

The DISORT2 solver was applied with 16 streams in the polar angle space and with the same number of Legendre expansion coefficients of the scattering phase function.

\section{Database of scattering properties of randomly oriented spheroidal homogeneous particles}

In order to compute the optical properties of non-spherical mineral dust particles for studying their effects on the radiation budget of the atmosphere, the scattering properties of single nonspherical model particles are needed before integrating over a size distribution.

As Fig. 2 demonstrates, Saharan mineral dust contains large particles. Thus, when performing radiative transfer simulations at wavelengths down to the UV the volume equivalent size parameter $x_{v}$ of these particles becomes very large with values up to 800 . Since no single scattering code is available covering the entire size parameter space, several methods had to be used to simulate scattering properties for single spheroidal model particles as a function of the parameters $x_{v}$, real $n_{r}$ as well as imaginary part $n_{i}$ of the complex refractive index and aspect ratio $\epsilon(\mathrm{AR})$ defining a four-dimensional parameter space. Four methods were driven to compute the data which were saved to a database. Table 2 gives information about the grid points of the database covering the parameter space and the applied methods at certain intervals of it. The comprehensive calculations for all combinations of these four parameters were extremely time-consuming and required nearly two years.

The database contains the following scattering properties for homogeneous and randomly oriented monodisperse prolate and oblate spheroids: the cross-section for extinction $C_{e}$ and scattering $C_{s}$, the single scattering albedo $\omega_{o}$, the asymmetry parameter $g$ and the scattering phase function $P$ with an angular resolution of $0.1^{\circ}$.

The null-field method (NFM) of Mishchenko (1991) can be considered as exact, however, only size parameters $x_{v}$ lower than $\sim 75$ can be considered for comprehensive database calculations (Table 2). The larger $x_{v}$, the smaller the covered ranges with respect to $n_{r}, n_{i}$ and $\epsilon$ where convergence was obtained. Thus we had to use the extended-precision version of this code (see the table). Following Mishchenko and Travis (1998) we use the notation of oblate spheroids with ARs $\epsilon>1$ and of prolates with $\epsilon<1$. The convergence parameter DDELT was specified as 0.000001 for most of the computations, and NPN4 as well as NDGS were chosen up to 250 and 34 to guarantee overall convergence (M. Mishchenko, personal communication). For larger $x_{v}$ we used the Geometric-optics-integral-equation method (GOIM) as well as the improved one (IGOIM). The number of traced rays $N_{\text {rays }}$, internal and external reflections $N_{\text {int }}$ and $N_{\text {ext }}$ as well as of particle orientations $N_{o}$ were specified as given next: $N_{\text {rays }}=3000000, N_{\text {int }}=10, N_{\text {ext }}=7$ and 
Table 2. Scattering methods used in certain ranges of the four-dimensional parameter space, defined by the volume equivalent size parameter $x_{v}$, the aspect ratio (AR) $\epsilon$ and the real $n_{r}$ as well as the imaginary part $n_{i}$ of the complex refractive index, for calculating the extinction optical properties of single randomly oriented prolate $(\epsilon<1)$ and oblate $(\epsilon>1)$ spheroids and saving these data in a database. Note that these ranges are approximate ones depending on the convergence of the several methods for given combinations of the parameters $x_{v}, n_{r}, n_{i}$ and $\epsilon$. Of course, we tried to obtain the maximum coverage of the parameter space for all methods

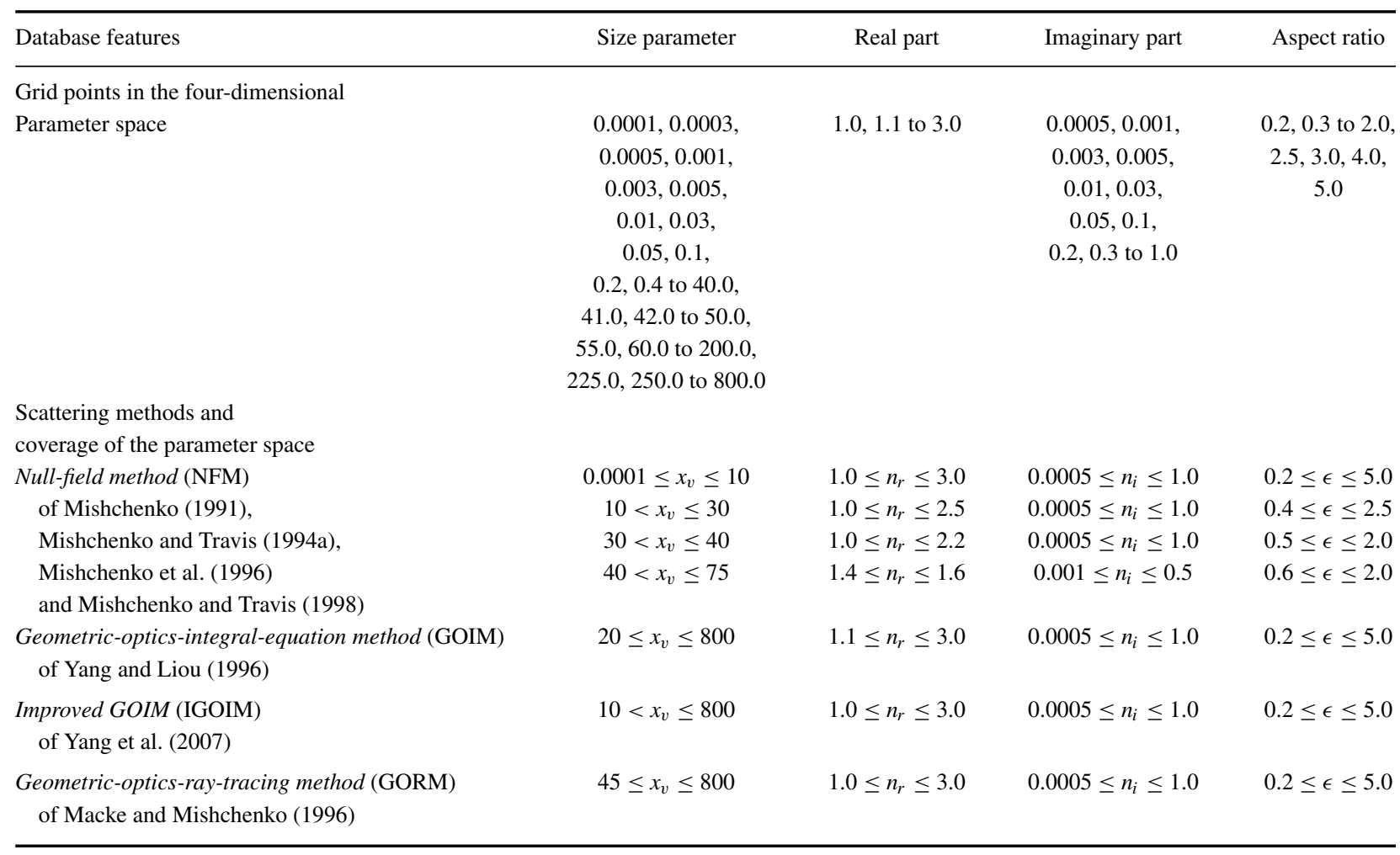

$N_{o}=30000$ (similar values also used by Dubovik et al., 2002b, 2006, pers. comm.). In the case of the Geometric-optics-raytracing method (GORM) we chose $N_{\text {rays }}=1000, N_{\text {int }}=100$ and $N_{o}=10000$ (Grenfell et al., 2005).

GOIM, IGOIM and GORM are geometrics-optics approximation (GOA) methods for large size parameters. However, GOIM and IGOIM can be used for smaller ones, too, for comparison with NFM, see Table 2. Comparing the scattering properties calculated by NFM, GOIM and IGOIM one can conclude that these GOA methods render the scattering properties as a function of the parameters $x_{v}, n_{r}, n_{i}$ and $\epsilon$, although deviations can occur for certain parameter combinations. It turned out that the results of IGOIM really improve those of GOIM in most of the cases compared to NFM. While GOIM overestimated $\omega_{o}$ due to a less correct description of the scattering, the values produced by IGOIM and GORM are more comparable to those of NFM. The disadvantage of GORM is that this method cannot reproduce a non-constant variation of the extinction efficiency $Q_{e}$ versus $x_{v}$, in the method it is set constant at 2 . However, $\omega_{o}$ seems to be more exact compared to GOIM and IGOIM. On the other hand, there are situations in which GOIM as well as GORM did and NFM as well as IGOIM did not converge. In such cases we used the $Q_{e}$ of GOIM and $\omega_{o}$ of GORM to recompute the scattering efficiency $Q_{s}$ (and thus $C_{s}$ ). The differences in $g$ using all methods were not significant.

In our calculations we first used the data of NFM if converging and of IGOIM if not. If IGOIM did not produce results we combined GOIM and GORM as discussed above. Finally, if there were no data from NFM, IGOIM and GOIM, we took them from GORM.

\section{Optical properties and atmospheric radiative effects of Saharan mineral dust}

The number concentration size distributions (Fig. 2) were measured within a dust plume at two constant altitudes from 11:23 to 12:06 UTC on 19 May onboard the FALCON around OZT (Weinzierl et al., 2008) during the flight from Casablanca Mohammed V International Airport to OZT (10:35-12:20 UTC, see Fig. 1). Number concentration measurements of the accumulation mode, that is, of particles with diameters of $0.1-3.0 \mu \mathrm{m}$ (Fig. 8, top), were carried out simultaneously during the whole flight where a maximum altitude of about $9.3 \mathrm{~km}$ was reached (Esselborn et al., 2008). Since our radiative transfer model 

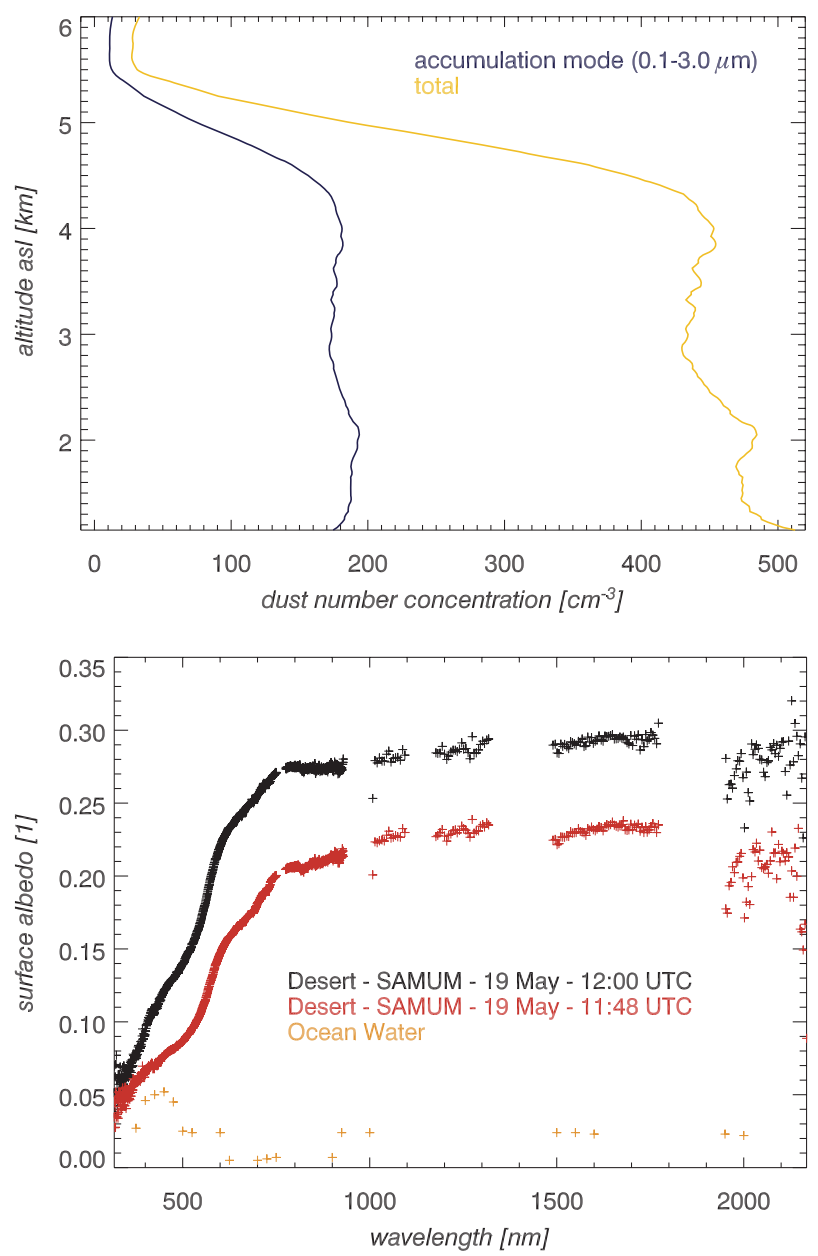

Fig. 8. (top panel) Number concentration of the accumulation mode (blue) measured on 19 May during the FALCON flight, which was scaled to the total (yellow), see the main text. (bottom panel) Spectral surface albedos measured on 19 May onboard the D-GERY at 11:48 and 12:00 UTC close to OZT ( $\sim 5 \%$ measurement uncertainty) compared to the surface reflectance characteristics of ocean water.

requires vertical information of the total number concentration of the dust for realistic comparisons of simulated optical properties to independent measurements, the size distribution data at the two levels could not provide such vertical information. Thus, we firstly averaged the accumulation data over the time span 10:50-12:20 UTC and smoothed them with respect to their altitude dependence to eliminate the roughness in these data. The blue curve in Fig. 8 (top) shows the mean profile of the accumulation mode concentration, which we treated to be representative for the area around OZT. On the other hand, we calculated the number concentrations of the accumulation mode as well as the total number concentrations with the help of the size distribution data at the two measurement levels. It turned out that at both levels the latter ones were larger than the former by the factor of $\sim 2.5$. Thus, we took this factor for scaling the mean accumulation mode profile in order to obtain a mean vertical profile of the total number concentration (we further changed it below $1700 \mathrm{~m}$ to be increasing with decreasing altitude according to the measured backscatter data in Fig. 10, top) for the OZT region at noontime, which is drawn as the yellow curve in Fig. 8 (top). At the same time ( 12:00 UTC) the OZT site was overflown by the D-GERY with the radiation measurement system onboard. This was the moment for which an optical closure could be achieved: Simulations of the optical properties and spectral irradiances could be performed, based on the measured local surface albedo (at the D-GERY) and in-situ particle data (FALCON) and be compared to the independent in-situ measurements of the optical properties from the lidars (HSRL onboard the FALCON and BERTHA at OZT) and to the spectral irradiances measured onboard the D-GERY and at OZT airport. In the following we will discuss these closure simulations and will distinguish between the consideration of spherical and non-spherical model particles. All computations were performed using the size distributions of Fig. 2 and the complex refractive indices of Fig. 6 for the airborne particles: The optical properties were simulated at the two measurement levels (Fig. 2), normalised to a number concentration of $1 \mathrm{~cm}^{-3}$ and linearly interpolated to the model levels between these two levels as well as assumed to be constant above and below them. Finally, the profiles of the optical properties were scaled by the measured total number concentrations of Fig. 8 (top). These optical properties were then taken for radiative transfer simulations using the spectral surface albedos, shown in Fig. 8 (bottom), as input.

\subsection{Spherical model particles}

The optical properties of the measured Saharan dust ensemble (Fig. 2) were simulated for 19 May using Mie scattering theory, whereby the dust plume was considered up to an altitude of $5.6 \mathrm{~km}$ a.s.1. in accordance to the observed atmospheric situation around OZT at noontime as discussed with the SAMUM field scientists. The resulting vertical spectral extinction coefficient (EC) and the spectral optical depth (SOD) are plotted in Fig. 9 (top and centre) in comparison to HSRL and BERTHA data at $532 \mathrm{~nm}$. Both lidar data sets are temporal averages: The HSRL profile was integrated over a time span of 119 s during the FALCON flight and is representative for the dust plume around OZT at 11:09 UTC. The BERTHA data was obtained by averaging the lidar signals measured at OZT in the morning from 9:59 to 11:16 UTC. The simulated profile of the EC at $532 \mathrm{~nm}$ is in accordance to these measurement data but shows a maximum of extinction at a larger altitude. This is probably a result of the fact that the size distribution at the measurement level 2 overestimates the extinction which leads to an overemphasised extinction above $\sim 4 \mathrm{~km}$ on the one hand, and it may also be the result of averaging the number concentrations during the FALCON flight (10:50-12:20 UTC, Fig. 8, top) to obtain an according profile on the other hand. In this context we reemphasise that no measured in-situ data of the total dust number 

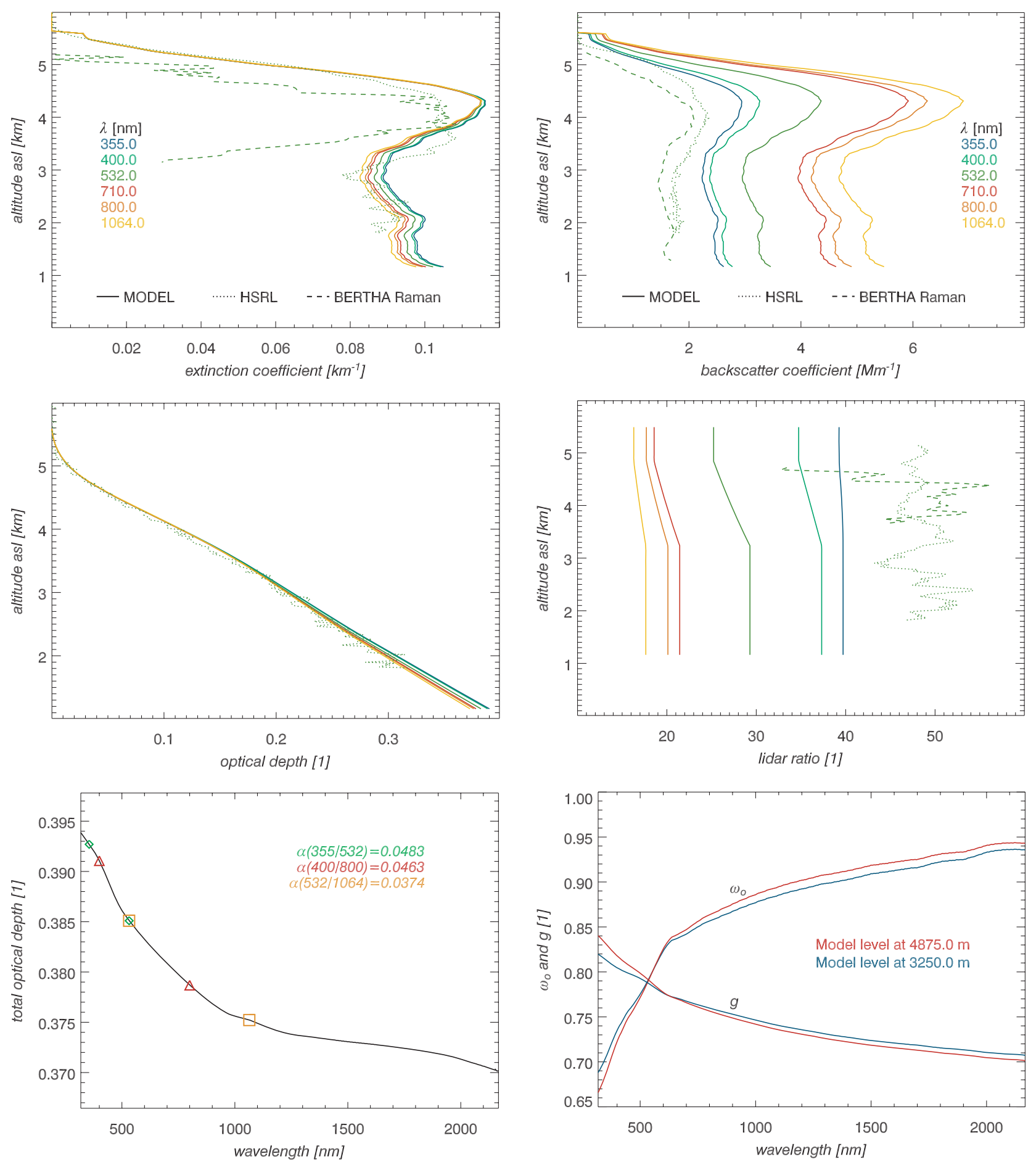

Fig. 9. (top panel) Modelled extinction coefficient (solid) on 19 May over OZT at 12:00 UTC for spherical model particles as function of the altitude for short-wave wavelengths compared to measurement data at $532 \mathrm{~nm}$ of the HSRL lidar (dotted) onboard the FALCON and of the BERTHA Raman lidar (dashed) located at OZT. (centre panel) As before but for the optical depths together with the HSRL data. (bottom panel) The respective total spectral optical depth and several Ångström exponents $\alpha$ after eq. (6).

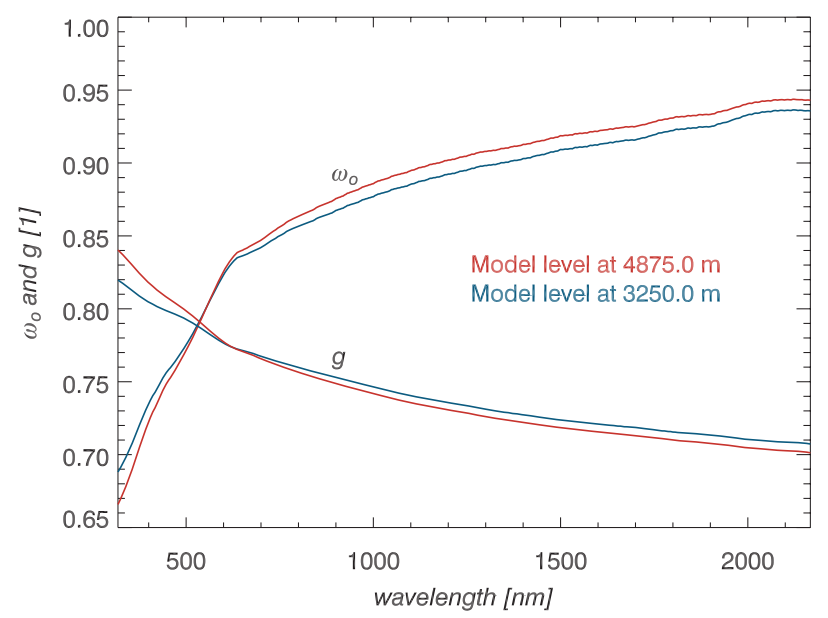

Fig. 10. (top panel) Modelled backscatter coefficient (solid) on 19 May over OZT at 12:00 UTC for spherical model particles as function of the altitude for short-wave wavelengths compared to measurement data at $532 \mathrm{~nm}$ of the HSRL lidar (dotted) onboard the FALCON and of the BERTHA Raman lidar (dashed) located at OZT. (centre panel) As before but for the lidar ratio. (bottom panel) The spectral single scattering albedo and asymmetry parameter simulated at the two measurement levels (Fig. 2). 

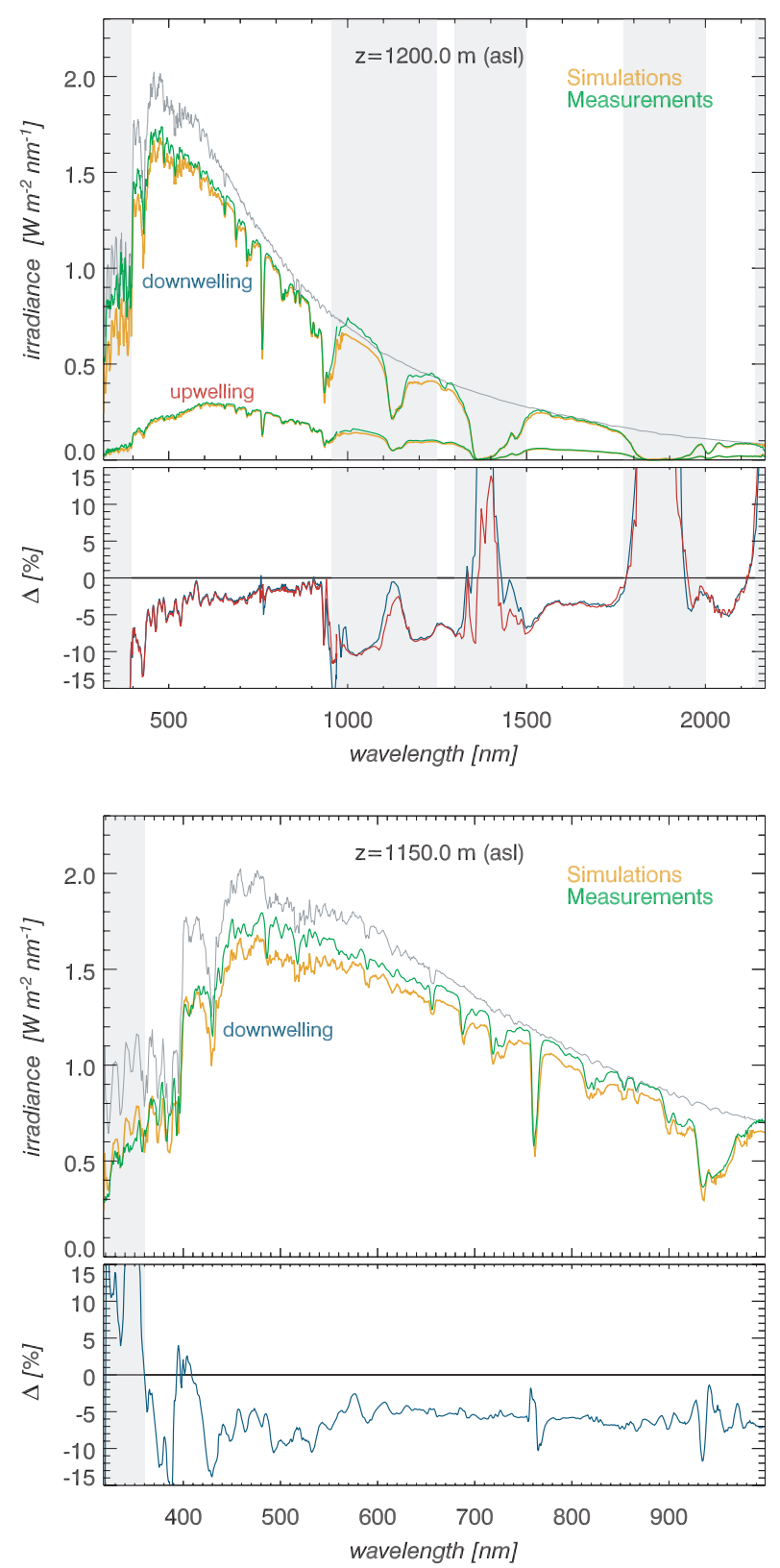

Fig. 11. Downward and upward spectral irradiances measured at the D-GERY (green) close to OZT at $\sim 50 \mathrm{~m}$ a.g.l. (upper panels) and at the OZT ground station at $0 \mathrm{~m}$ a.g.1. (lower panels) on 19 May at 12:00 UTC ( $\sim 3 \%$ measurement uncertainty) compared to the modelled spectra (yellow). Secondary panels: Differences between the modelled and measured downwelling (blue) as well as upwelling (red) spectra; Grey curves: extraterrestrial radiative flux density at TOA corrected to the actual Earth-Sun distance and local solar zenith angle (SZA) of $\sim 12.5^{\circ}$.

concentration were available, and, furthermore, one has to keep in mind temporal variabilities of the dust plume which changes its vertical structure on time scales of minutes (Tesche et al., 2008) due to so-called dust devils and convection (Ansmann et al., 2008). This can explain the differences between the mea-

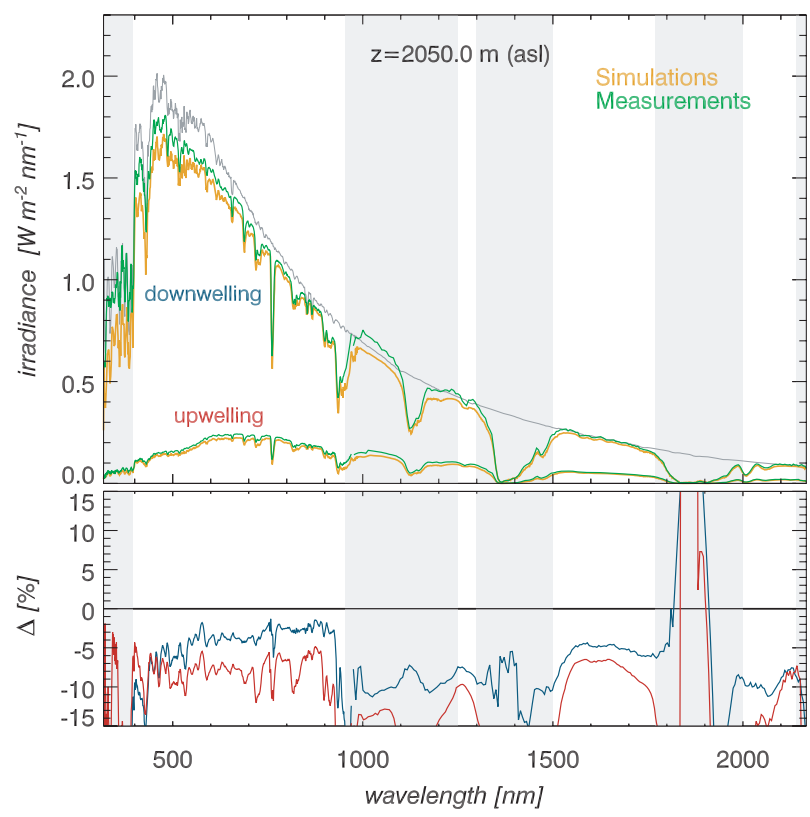

Fig. 12. Downward and upward spectral irradiances measured at the D-GERY (green) close to OZT at $\sim 900 \mathrm{~m}$ a.g.1. on 19 May at 11:48 UTC ( $\sim 3 \%$ measurement uncertainty) compared to the modelled spectra (yellow). Secondary panel: Differences between the modelled and measured downwelling (blue) and upwelling (red) spectra; Grey curve: extraterrestrial radiative flux density at TOA corrected to the actual Earth-Sun distance and local SZA of $\sim 13.7^{\circ}$.

sured lidar data, which were representative for approximately 11:00 UTC, and the closure simulations made for 12:00 UTC which show a slight overestimation of the SOD compared to the HSRL measurements. However, the values of the total optical depths of $\sim 0.39$ around $500 \mathrm{~nm}$ simulated in the morning are still lower than the $\sim 0.42$ observed at OZT using sun photometers (Tesche et al., 2008).

Figure 9 (bottom) shows the spectral dependence of the total SOD $\tau(\lambda)$ which can be expressed by the Ångström exponent defined as

$\alpha\left(\lambda_{1} / \lambda_{2}\right)=-\frac{\ln \left[\frac{\tau\left(\lambda_{2}\right)}{\tau\left(\lambda_{1}\right)}\right]}{\ln \left(\frac{\lambda_{2}}{\lambda_{1}}\right)} \quad\left(\lambda_{2}>\lambda_{1}\right)$

for the wavelength interval $\left[\lambda_{1}, \lambda_{2}\right]$. The larger the values of $\alpha$, the stronger is the gradient in the optical depth $\tau(\lambda)$, which usually decreases with increasing wavelength. The simulation on 19 May led to values of $\sim 0.044$ within the spectral range between 355 and $1064 \mathrm{~nm}$ which were in agreement to $\sim 0.03$ obtained by Wiegner et al. (2008). Such small values can be traced back to the presence of a dominant fraction of large particles as in the case of the dust plume observed on SAMUM's 19 May (Fig. 2).

While the extinction coefficient is well described by the model of spherical particles, the Mie simulations of the backscatter coefficient (BSC) according to eq. (4) and the lidar ratio (LR) following eq. (5) are not in agreement with the experimental 
data: The Figures 10 (top) and (centre) depict the modelled BSC and LR compared to lidar data measured at the wavelength of $532 \mathrm{~nm}$. Obviously dust particles are not of spherical shape, and these present non-spherical particles show diminished backscattering in comparison to assumed spheres, which leads to larger measured LRs. However, this 'backscattering' is defined with respect to the exact backward direction, see eq. (4), and does not mean automatically that less downward radiation is backscattered upwards. Only a quantitative comparison of the spectral asymmetry parameter of the non-spherical particles described here by spheroids to spherical ones can give such information (Section 5.2).

The single scattering albedo $\omega_{o}$ and asymmetry parameter $g$ of the dust is presented versus wavelength in Fig. 10 (bottom) for the two levels where the size distributions were measured, and mean values of $\omega_{o}=0.79$ and $g=0.79$ were computed at $532 \mathrm{~nm}$, compared with $\omega_{o}=0.76$ and $g=0.81$ at $550 \mathrm{~nm}$ in a recent study (Otto et al., 2007), confirming the absorbing and forward scattering properties of Saharan mineral dust. These low/large values of $\omega_{o} / g$ are mainly caused by the contribution of coarse mode particles in the dust population (Otto et al., 2007).

Using the spherical optical properties as discussed before, as well as the spectral surface albedo or Fig. 8 (bottom), the radiation field of the dust plume was simulated. The upper panels of Fig. 11 show the modelled downwelling and upwelling spectral irradiance from 318 to $2167 \mathrm{~nm}$ compared to the measurements onboard the D-GERY at an altitude of only $\sim 50 \mathrm{~m}$ above OZT at 12:00 UTC, whereby our fine-band spectra were smoothed to match the spectral variations in the measured data. The measurement uncertainties amount to about $3 \%$ in the irradiance and $\sim 5 \%$ in the surface-albedo data (Bierwirth et al., 2008). The deviations between simulation and measurement are within 5\% for most parts of the spectral range. The grey boxes indicate regions for which large errors of measurement were expected (see Bierwirth et al., 2008, for details). The model spectra slightly underestimates the measured. This indicates that the simulated optical depth probably overestimates the true local one as we mentioned above with regard to Fig. 9 (centre). The lower panels of Fig. 11 depict the comparison of simulation and observation for the same situation as before but at ground level. However, here the deviation between model and measurement is larger (5-10\%). But note that the ground-measured irradiances above $400 \mathrm{~nm}$ were by up to $5 \%$ larger than those at the higher altitude of $\sim 50 \mathrm{~m}$ a.g.l. presented in the top panels. This indicates that these ground observations were dependent on the local environmental conditions at OZT. On the other hand, the D-GERY was very close to the place of the ground measurements at the considered time within a distance of $\sim 1 \mathrm{~km}$, and this discrepancy of 5\% may also be interpreted as the local variability in the irradiance for altitudes very close to the surface.

The same dust optical properties were taken for a radiative transfer simulation at 11:48 UTC at which the D-GERY reached the highest altitude of $\sim 900 \mathrm{~m}$ a.g.l. on 19 May. The respective measured surface albedo is plotted in Fig. 8 (bottom), which was up to $30 \%$ lower than in the case of the situation at 12:00 UTC. This shows the local variability of the spectral surface reflectivity which is important for the upwelling transport of radiation. Figure 12 (top) presents the simulated and measured irradiances for this case study. The spectral deviations between simulation and observation (bottom) are slightly larger as compared to the case of 12:00 UTC. We trace this back to the temporal variability of the dust plume and its optical properties, for which no observational data were available. On the other hand the backscattering properties of the true non-spherical particles (see the following section) may have an increasing effect on the upwelling radiation field at such higher altitudes.

\subsection{Optical properties of spheroidal model particles}

If one considers non-spherical particles of an aerosol population described by a size distribution as in eq. (1), one has to think about what the 'size' $D_{p}$ means. It simply depends on a definition, if field scientists do not provide information about this parameter. To demonstrate its importance, five cases were defined in which $D_{p}$ in the size distributions (shown in Fig. 2) of spheroidal model particles could be interpreted as follows:

(i) $D_{p}$ is the diameter of a sphere having the same volume as the spheroid

(ii) $D_{p}$ is the diameter of a sphere having the same surface area as the spheroid

(iii) $D_{p}$ is the diameter of a sphere having the same volumeto-surface area ratio as the spheroid

(iv) $R_{p}=\frac{1}{2} D_{p}$ is the length of the longest half-axis of the spheroid (maximum dimension)

(v) $R_{p}=\frac{1}{2} D_{p}$ is the length of the shortest half-axis of the spheroid (minimum dimension)

Note that we did not change the observed size distributions, as it could not be done, e.g., by keeping constant the total volume or surface of an assumed spherical particle ensemble when varying size equivalence. We simply want to investigate the shape effects using always the same size distributions provided by the field scientists. Further one has to keep in mind that each model spheroid can have a certain aspect ratio (AR) $\epsilon=\frac{b}{a}$ where $a$ is always the rotational axis and $b$ the other half-axis. The case $b>a$ means an oblate spheroid leading to $\epsilon>1$, and $b<a$ means a prolate one resulting in $\epsilon<1$. The volume $V$ and surface area $S$ of an oblate or prolate spheroid can then be written as

$$
\begin{aligned}
V(a, \epsilon) & =\frac{4}{3} \pi a^{3} \epsilon^{2} \quad S(a, \epsilon)=2 \pi a^{2} f_{s}(\epsilon) \\
f_{s}(\epsilon) & = \begin{cases}\epsilon^{2}+\frac{\epsilon}{\sqrt{\epsilon^{2}-1}} \sinh ^{-1}\left(\sqrt{\epsilon^{2}-1}\right) & \epsilon>1 \\
\epsilon^{2}+\frac{\epsilon}{\sqrt{1-\epsilon^{2}}} \sin ^{-1}\left(\sqrt{1-\epsilon^{2}}\right) & \epsilon<1\end{cases}
\end{aligned}
$$

where $f_{s}$ is a shape factor depending only on the AR. 
The single scattering optical properties of homogeneous and randomly oriented monodisperse spheroids were saved in a database (Table 2) as described in Section 4. Since these were stored as function of the volume equivalent size parameter

$x_{v}=\frac{\pi D_{v}}{\lambda}$,

this quantity has to be computed before extracting data from the database. Thus, for a considered wavelength $\lambda$ the volume equivalent diameter $D_{v}$ must be determined for each model particle having the 'size' $D_{p}$ when integrating over the size distribution of the dust to calculate its polydisperse optical properties. This means for our five cases of volume equivalence (VEQV), surface equivalence (SEQV), volume-to-surface area equivalence (VSEQV), longest axis equivalence (LAEQV) and shortest axis equivalence (SAEQV) that

(i) $D_{v}=D_{p}$

(ii) $D_{v}=D_{p} \epsilon^{\frac{2}{3}}\left[\frac{1}{2} f_{s}(\epsilon)\right]^{-\frac{1}{2}}$

(iii) $D_{v}=D_{p} \epsilon^{-\frac{4}{3}} \frac{1}{2} f_{s}(\epsilon)$

(iv) $D_{v}=D_{p} \epsilon^{\frac{2}{3}}$ (prolates), $D_{v}=D_{p} \epsilon^{-\frac{1}{3}}$ (oblates)

(v) $D_{v}=D_{p} \epsilon^{-\frac{1}{3}}$ (prolates), $D_{v}=D_{p} \epsilon^{\frac{2}{3}}$ (oblates).

In the following we consider ARs of up to the axis ratio of $1: 2.0$, that is, $\epsilon$ down to 0.5 for prolate and up to 2.0 for oblate spheroids. This range covers the maxima in the AR distributions observed during SAMUM at axis ratios from 1:1.3 to 1:1.6, see Section 2.6. Note that no information was available from these measurements on whether the particles showed rather oblate or prolate shapes. Further, we always assumed a certain constant AR with respect to all particles in the measured dust size distributions for each simulation of the spectral optical properties. On the one hand this minimises computational effort but, on the other hand, the main goal of this assumption is to represent a plausible mixture of ARs by an effective AR (Mishchenko and Travis, 1994b). By comparing the simulated optical properties as function of AR with independent lidar measurements we hope to estimate the effective particle shape of the Saharan mineral dust observed on 19 May during SAMUM, and also with regard to the results of the SPAs.

Figure 13 presents the simulated deviations of the spectral single scattering albedo $\omega_{o}$ (dotted) and asymmetry parameter $g$ (solid) of the measured dust approximated by spheroids as function of the AR for VEQV (top), SEQV (centre) and VSEQV (bottom) from the computed $\omega_{o}$ and $g$ via Mie theory. The considered altitude of $2225 \mathrm{~m}$ a.g.1. (3375 $\mathrm{m}$ a.s.1.) was chosen to demonstrate the non-sphericity effects on the optical properties between the two measurement levels (Fig. 2) at the centre of the dust plume, which extended up to a maximum altitude of $5.6 \mathrm{~km}$ a.s.l. Assuming the three equivalence cases and moderate axis ratios up to 1:2.0 it turned out that spherical-spheroidal differences are relatively small but seem to be larger than reported by Mishchenko (1993), but note that such quantitative comparisons are critical due to the use of different complex refractive

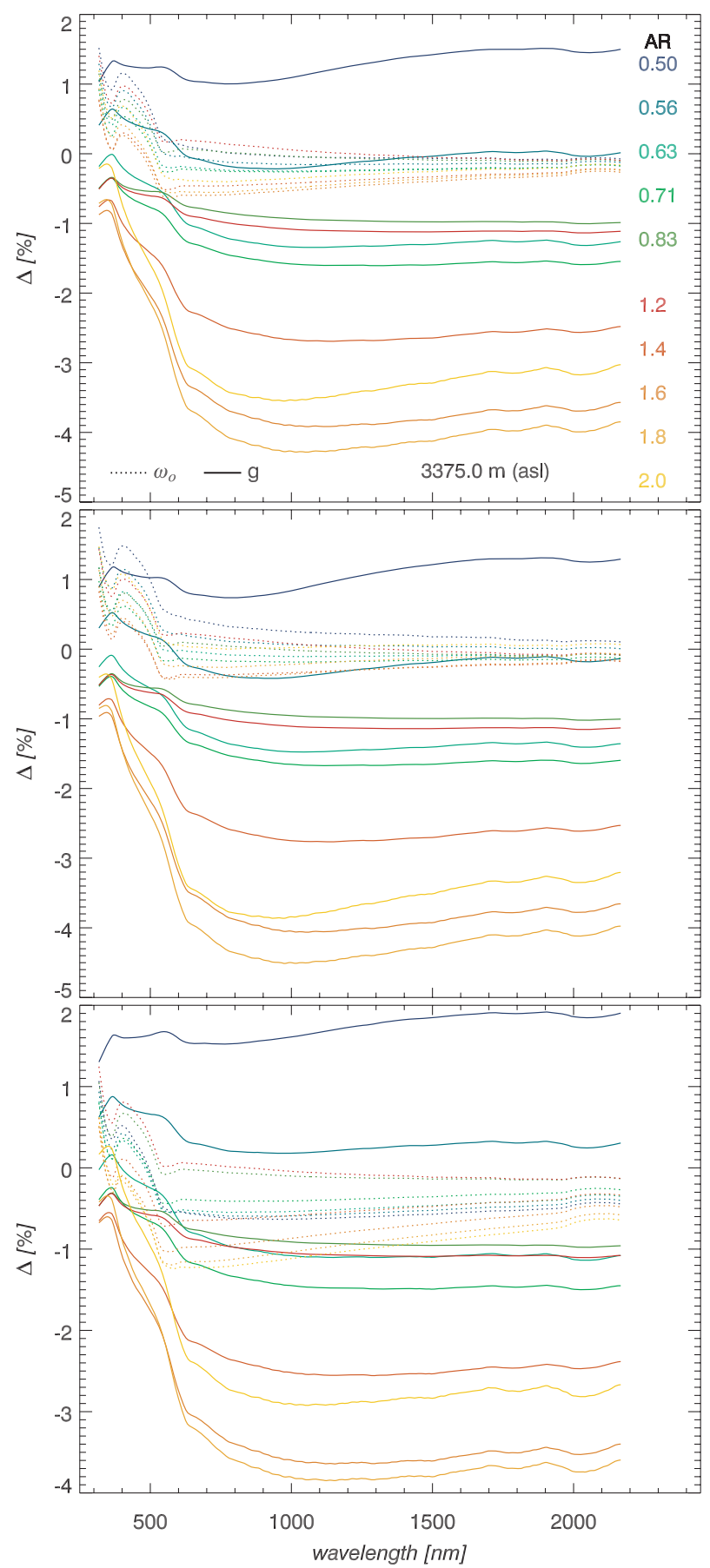

Fig. 13. Deviations in $\omega_{o}$ (dotted) and $g$ (solid) for prolate (AR $\epsilon<1$ ) and oblate $(\mathrm{AR} \epsilon>1)$ spheroids from Mie theory on 19 May over OZT at 12:00 UTC at an altitude of $2225 \mathrm{~m}$ a.g.l. (top panel) VEQV. (centre panel) SEQV. (bottom panel) VSEQV.

indices and size distributions. According to that work the reason for these larger deviations may be that the influence of shape is more relevant for larger effective radii of the dust population, as in our case of dust containing a significant fraction of large 
particles (Fig. 2). The spherical-spheroidal differences here are within $\pm 1 \%$ for $\omega_{o}$ and range from -5 to $2 \%$ for $g$ strongly depending on wavelength. These values are similar to Mishchenko et al. (1996) who also found that $g$ is more sensitive than $\omega_{o}$ to AR variations for large effective size parameters. Moreover, for most of the wavelengths and increasing axis ratios both $\omega_{o}$ and $g$ decrease firstly, but increase for even larger ARs (Mishchenko et al., 1996). Since the spherical-spheroidal deviations are rather negative for oblate and positive for prolate spheroids, the oblate are slightly more absorbing and significantly more backscattering than the prolate of the same AR (Mishchenko and Travis, 1994b; Mishchenko et al., 1996).

Figure 13 merely depicts the shape dependent spectral $\omega_{o}$ and $g$ for the cases VEQV, SEQV and VSEQV which show no significant qualitative differences between each other. We also simulated the two cases of LAEQV and SAEQV. For LAEQV the spectral spherical-spheroidal differences in $\omega_{o}$ are always positive $(0-6 \%)$ and negative in $g(-6$ to $0 \%)$ for the considered ARs. Vice versa in the case of SAEQV, the respective deviations are mainly negative in $\omega_{o}(-5$ to $+1 \%)$ and positive in $g(-2.5$ to $+3 \%$ ) for most of these shapes. Again, both optical properties show larger values for prolate particles compared to oblate ones for the same AR and for most of the wavelengths.

The non-sphericity effects of the model spheroids on the total SODs of absorption, scattering and extinction $\tau_{a, s, e}$ are shown in Fig. 14. In contrast to $\omega_{o}$ and $g$ (Fig. 13) the cases VEQV, SEQV and VSEQV lead to strongly different deviations from the Mie computations (Fig. 9, bottom). First, VEQV leads to optical depths which can increase by up to $10 \%$ in the considered range of ARs, always with stronger effects for oblate compared to prolate shapes. The non-sphericity effects are almost positive, which increase with increasing axis ratio of the spheroidal model particles. Second, for SEQV the effects of the non-spherical particle shapes on the SODs show strongly different variations with AR and wavelength. The main difference to the case of VEQV is that the extinction optical depth decreases with increasing axis ratio, whereby the effects are smaller (within $-3 \%$ ) compared to VEQV. Again, the spherical-spheroidal differences of oblate spheroids are larger than those of prolate. Third, the case of VSEQV results in similar qualitative spectral sphericalspheroidal deviations as for VEQV. However, the magnitudes of these effects are significantly larger with increases of up to $40 \%$. Moreover, simulations were also performed for the situations of LAEQV and SAEQV. These two cases led to strongly diminished (up to $-70 \%$ ) and increased (up to $+300 \%$ ) total SODs, respectively, within the considered range of ARs. Recall that the Mie simulations yield $\tau_{e} \sim 0.39$ around $500 \mathrm{~nm}$ compared to the independent sun photometer measurements for the Saharan dust scenario on 19 May over OZT at noontime of $\sim 0.42$, a difference of $+7.7 \%$ (Section 5.1). This indicates that the assumptions of LAEQV and SAEQV are definitely not realistic to describe the non-sphericity of mineral aerosol particles with regard to the total SOD due to the deviations mentioned above being too large

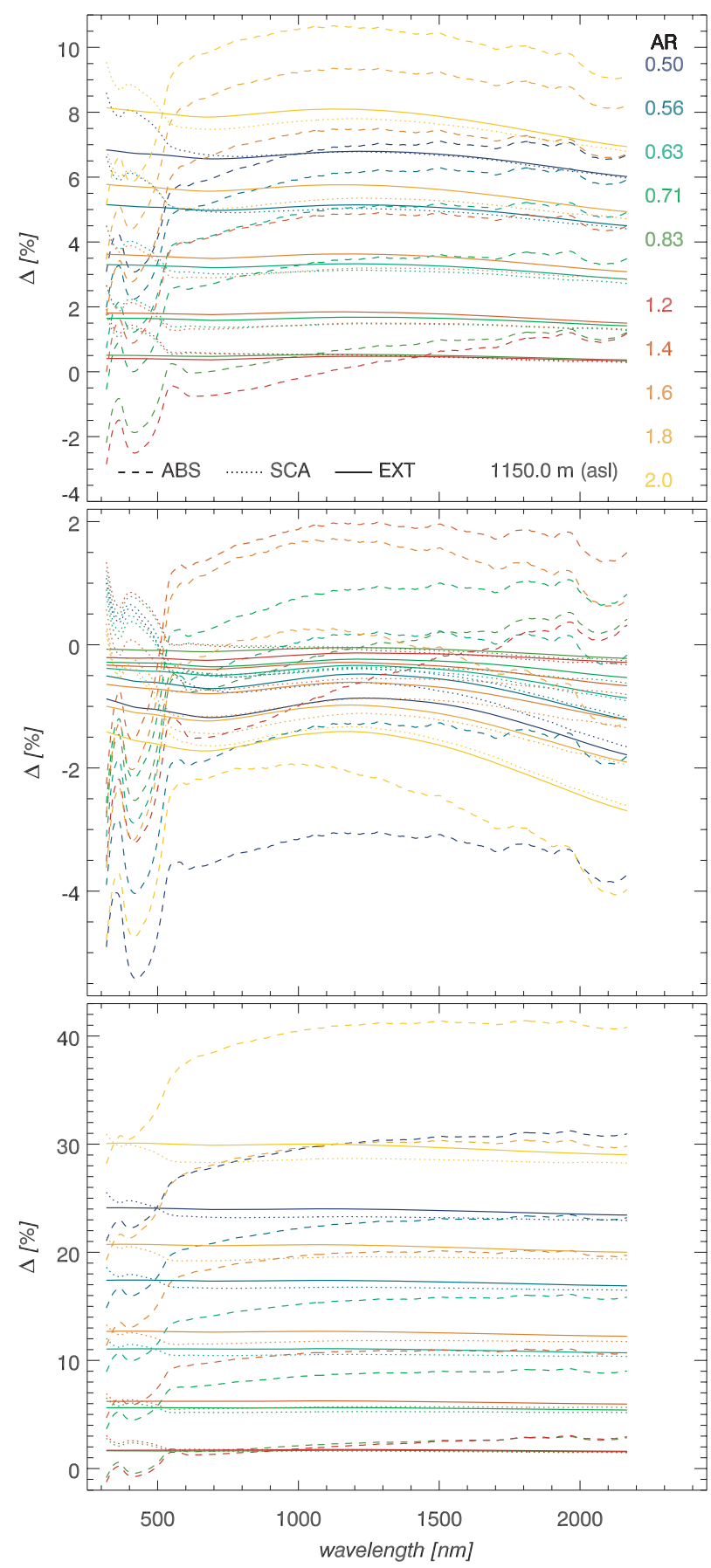

Fig. 14. Deviations in $\tau_{a, s, e}$ (dashed, dotted, solid) for prolate (AR $\epsilon<$ 1) and oblate (AR $\epsilon>1$ ) spheroids from Mie theory on 19 May over OZT at 12:00 UTC at BOA. (top panel) VEQV. (centre panel) SEQV. (bottom panel) VSEQV.

and that the case of SEQV may also not be representative, since these deviations are negative in that case. On the other hand, the sun photometer observations showed larger and smaller values of $\tau_{e}$ at smaller and longer wavelengths (Tesche et al., 2008) compared to Mie calculations (Fig. 9, bottom). 
However, all our equivalence cases demonstrated either positive or negative spherical-spheroidal deviations over the entire spectral range considered. We trace lower optical depths at longer wavelengths back to the fact that the diffuse light was not corrected in the skylight observations as reported by the field scientists, which can lead to underestimations of the SOD (Schmid et al., 2003). Corrected optical depths may top the Mie computations confirming the above-mentioned conclusion that the cases VEQV and VSEQV remain to be most representative to describe the non-sphericity of dust. Especially, for VEQV/VSEQV and oblate spheroids with an AR of $\epsilon=1.6$, the most probable aspect ratio for larger particles observed by the SPAs (Section 2.6 ), the total SOD for extinction is increased by up to $\sim 4 / 12 \%$. These values compared to the $+7.7 \%$ from above may indicate that VEQV is more realistic than VSEQV (Yang et al., 2004). To illuminate this question we will now investigate the role of effective shapes on the backscattering of the particles.

In Fig. 15 the backscatter coefficients (BSCs), simulated at $532 \mathrm{~nm}$ for various oblate and prolate shapes, are drawn versus altitude in comparison to the case of spherical model particles (Fig. 10, top) and the independent lidar measurements. Our computations demonstrate that the backscattering of slightly non-spherical spheroids with axis ratios of $\sim 1: 1.1-1.3$ is larger than for spheres (Mishchenko and Travis, 1994b), however, for stronger non-spherical ones it decreases significantly (Mishchenko et al., 1996). This decrease is more dominant for prolate than for oblate particle shapes confirming the fact that the backscattering of oblate spheroids is larger than for prolate of the same AR due to higher values in their phase functions in backward directions (Mishchenko et al., 1996; Xie et al., 2007).

Analogously to the BSC (Fig. 15) we compared the lidar ratio (LR) simulated at $532 \mathrm{~nm}$ to the independent measurements (Fig. 10, centre). The results are shown in Fig. 16 and demonstrate that the LR for moderate oblate and prolate spheroids is lower than in the case of spheres, but for axis ratios of $\sim 1: 1.3-$ 2.0 it increases dramatically. As in the case of the BSC, the LR is more sensitive to changes in the AR for prolate spheroids, always showing larger values compared to oblate ones and indicating their different backscatter properties.

Both figures will now be used for a concomitant quantitative comparison of our simulations of BSC and LR to the in-situ observations in order to estimate a characteristic shape and an effective AR of the dust particles, independent from the single particle analyses (SPAs) as reported in section 2.6. For this, one has to find ARs and the respective curves in the two figures which determine ranges that approximately cover the curves of the measurements. This was done concomitantly for both the BSC as well as the LR in our five cases VEQV, SEQV, VSEQV, LAEQV and SAEQV as well as for oblate and prolate particles. The resulting AR ranges are presented in Table 3. First, the case SAEQV does not describe the BSC for assumed oblate shapes, and BSC as well as LR are not consistently reproduced using prolate particles. The same holds for LAEQV. Thus, both equiv-
Table 3. Ranges in the axis ratio of oblate and prolate spheroidal model particles for which an approximate agreement of the simulated BSC and LR with the independent lidar measurements were obtained, comparing the respective curves in the Figs. 15 and 16

\begin{tabular}{lccccc}
\hline & \multicolumn{2}{c}{ Oblate } & & \multicolumn{2}{c}{ Prolate } \\
\cline { 2 - 3 } \cline { 5 - 6 } & BSC & LR & & BSC & LR \\
\hline VEQV & $1: 1.5-1.7$ & $1: 1.5-1.7$ & & $1: 1.4-1.6$ & $1: 1.3-1.5$ \\
SEQV & $1: 1.5-1.7$ & $1: 1.5-1.7$ & & $1: 1.4-1.6$ & $1: 1.3-1.5$ \\
VSEQV & $1: 1.6-2.0$ & $1: 1.5-1.7$ & & $1: 1.4-1.6$ & $1: 1.3-1.5$ \\
LAEQV & $1: 1.4-1.6$ & $1: 1.5-1.7$ & & $1: 1.3-1.5$ & $1: 1.4-1.6$ \\
SAEQV & & $1: 1.4-1.6$ & & $1: 1.5-1.9$ & $1: 1.3-1.5$ \\
\hline
\end{tabular}

alence assumptions seem not to be representative in describing the non-sphericity of SAMUM's Saharan mineral dust. As mentioned above these two approaches led to unrealistic deviations in the SODs, too. Second, although SEQV reproduces BSC and LR consistently for oblate spheroids, this assumption led to decreased SODs compared to Mie theory which was concluded above to be not representative. Third, from the remaining cases of VEQV and VSEQV only the former one is able to describe the measurements using the same range of considered ARs: Volume equivalent oblate model particles with an effective mean axis ratio of $\sim 1: 1.6$ match the independent lidar observations on SAMUM's 19 May at noontime best. It is interesting to note that the ARs of the large particles, as measured utilising SPAs (Section 2.6), were also distributed around the axis ratio. This underlines the key role of this particle fraction with regard to the optical properties of Saharan mineral dust, which are obviously affected by its effective non-spherical shape. Further, the conclusion of Yang et al. (2004) seems to be confirmed that VEQV is more realistic than VSEQV to describe the single scattering properties of non-spherical particles approximated by spheroids.

We emphasize that the procedure used here only provided model simulations with best match of the lidar and sun photometer data to estimate the most probable size equivalence, particle shape and effective aspect ratio of assumed model spheroids, to the best of our knowledge. Of course, uncertainties in the measured or other input data can lead to deviations from the presented results. Moreover, the spheroid approximation itself can be seen as a rather simplified treatment in representing natural particles which may also be partially concave (Mishchenko and Travis, 1994b) or rough (Rother et al., 2006).

Finally, we want to discuss the ensemble optical properties of SAMUM's Saharan mineral dust assuming volume equivalent oblate spheroidal model particles of an effective AR of $\epsilon=1.6$, found to yield the best match as previously demonstrated.

Compared to Mie theory the deviations in $\omega_{o}$ vary from -0.5 to $1.0 \%$ (Fig. 13). Thus, the particle non-sphericity only slightly changes $\omega_{o}$ so that the relatively low value of $\sim 0.8$ at $550 \mathrm{~nm}$ 


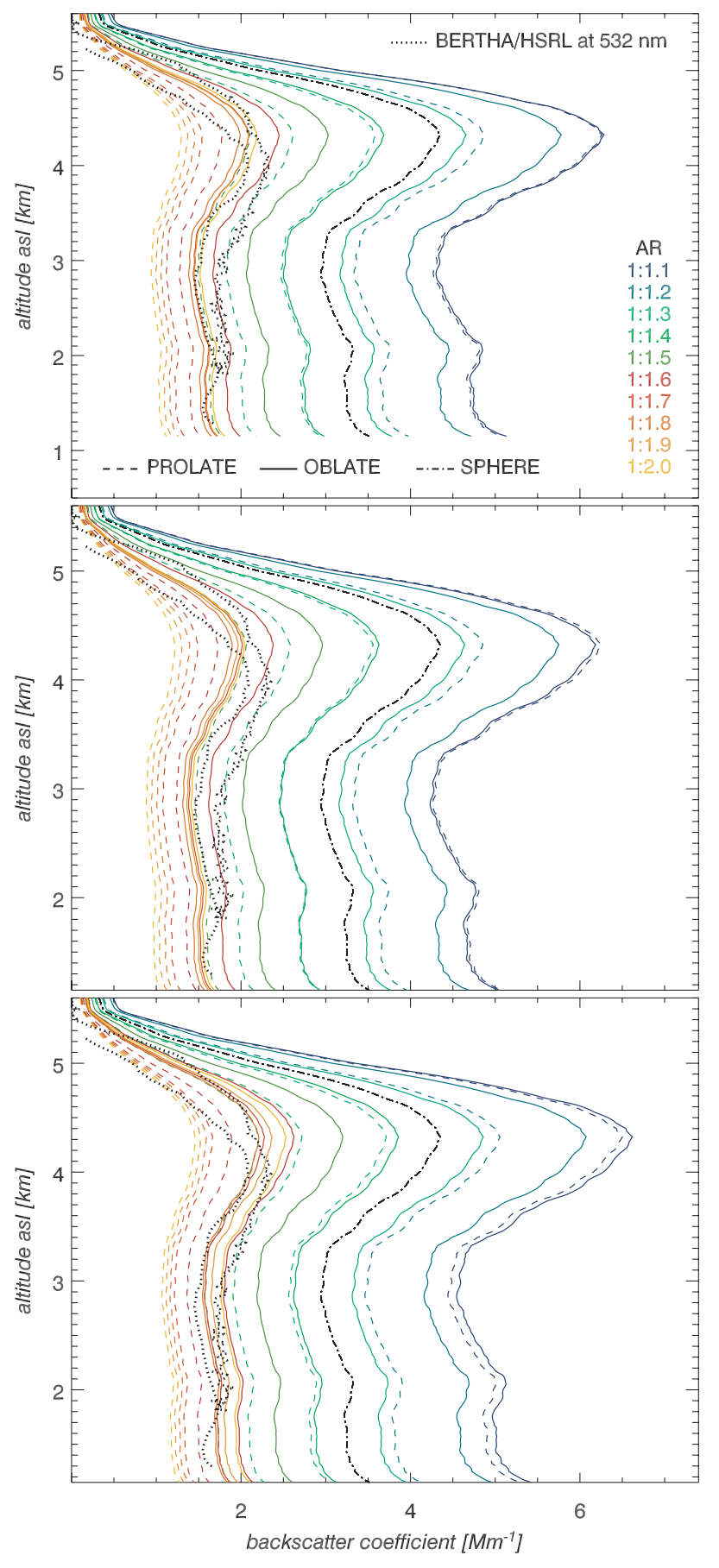

Fig. 15. Backscatter coefficients at a wavelength of $532 \mathrm{~nm}$ versus altitude simulated on 19 May over OZT at 12:00 UTC (coloured curves), as function of the axis ratio of assumed prolate (dashed) and oblate (solid) spheroids compared to independent observational data (dotted) of the lidar instruments BERTHA and HSRL. (top panel) VEQV. (centre panel) SEQV. (bottom panel) VSEQV. The case of considered spherical model particles (dashed-dotted) is the same as in Fig. 10 (top panel).

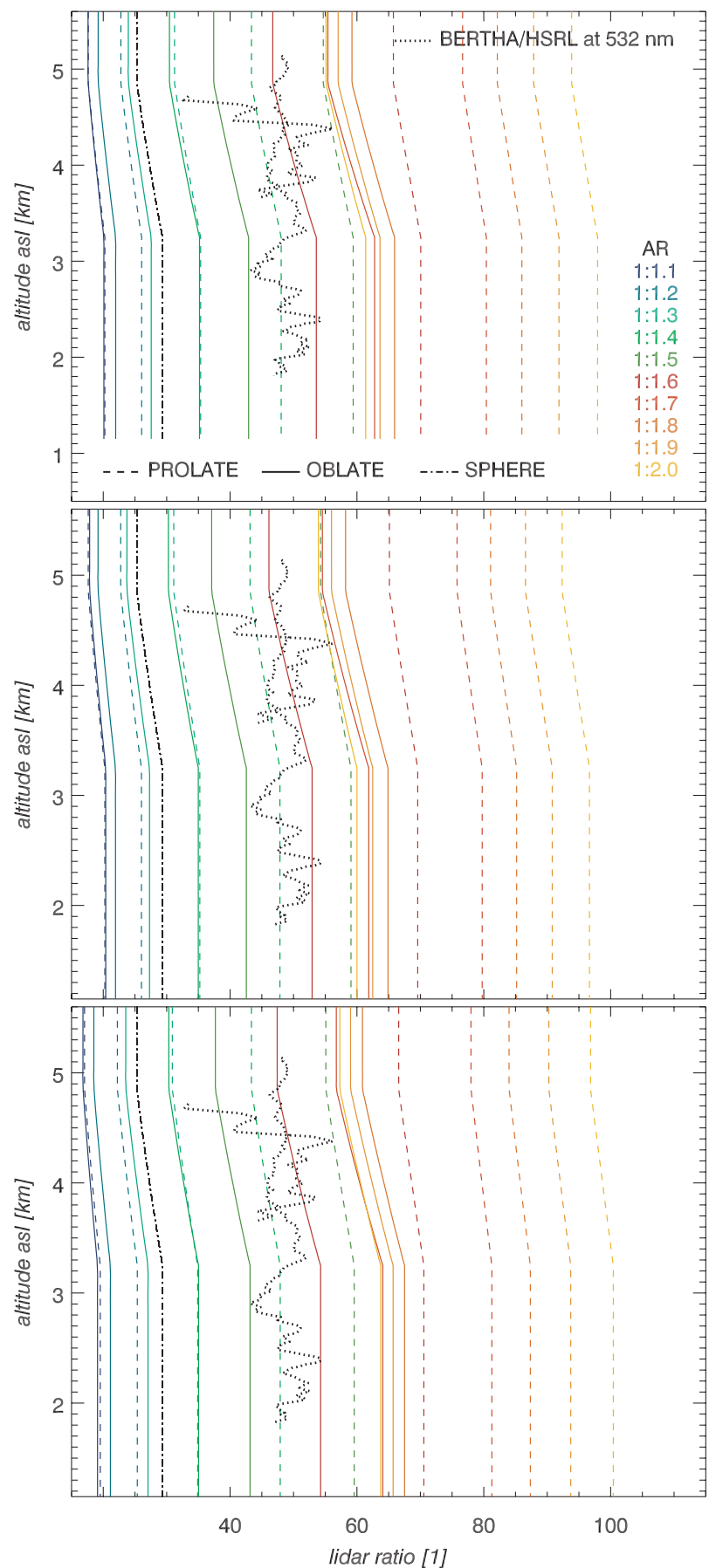

Fig. 16. Lidar ratio at a wavelength of $532 \mathrm{~nm}$ versus altitude simulated on 19 May over OZT at 12:00 UTC (coloured curves), as function of the axis ratio of assumed prolate (dashed) and oblate (solid) spheroids compared to independent observational data (dotted) of the lidar instruments BERTHA and HSRL. (top panel) VEQV. (centre panel) SEQV. (bottom panel) VSEQV. The case of considered spherical model particles (dashed-dotted) is the same as in Fig. 10 (centre panel). 
derived by Mie theory is also representative for the observed nonspherical dust particles. Wiegner et al. (2008) computed values of $0.77-0.90$ depending on the uncertainties in the complex refractive index, the choice of certain particle shapes and various shape distributions as well as on the consideration of large particles up to surface equivalent diameters of $20 \mu \mathrm{m}$. Olmo et al. (2008) derived values for $\omega_{o}$ down to 0.82 at $670 \mathrm{~nm}$ during a Saharan dust outbreak indicating even lower values at $550 \mathrm{~nm}$. On the other hand, assuming only fine mode particles of desert aerosols, thus neglecting large particle effects, $\omega_{o}$ can also be larger with values of $0.87-0.90$ (Kahnert, 2004). If the large particles are completely ignored, e.g. due to certain limitations of measuring or retrieving them, values for $\omega_{o}$ even larger than 0.90 can be obtained, which are then not representative for mineral dust (Dubovik et al., 2002a; Haywood et al., 2003) containing coarse mode particles. If a very low imaginary part is assumed additionally, even more unrealistic values close to 1 may be obtained (Osborne et al., 2008). This fact was also reported by Otto et al., (2007). To underline this we can refer to Schladitz et al. (2008) who derived comparable large values of $\omega_{0} \sim 0.95$ at $537 \mathrm{~nm}$ during SAMUM using a combined method, exploiting measured size distributions as well as absorption and scattering data of collected dust samples, restricted to the investigation of smaller particles due to certain instrument cut-offs.

Since $g$ is diminished due to the non-sphericity of the dust particles by 1.0 to $4.0 \%$ (Fig. 13), meaning an increased hemispherical backscattering, this might be important for the upward radiative transport above the dust plume (see the following section).

The total SODs are increased by up to $+7.5 \%,+4.5 \%$ and $+3.5 \%$ in absorption, scattering and exinction in comparison to spheres (Fig. 14) so that $\tau_{e}$ rises slightly from $\sim 0.39$ to $\sim 0.40$ around $500 \mathrm{~nm}$.

\subsection{Radiative effects of spheroidal model particles}

In order to quantify the above-mentioned backscattering effects of the assumed oblate spheroidal dust particles we considered the same scenario as in Fig. 11, that is, the 19 May over OZT at 12:00 UTC, but using oblate model particles with an axis ratio of 1:1.6 instead of spheres. We computed the downwelling and upwelling spectral irradiances at TOA, directly above the dust plume at $4850 \mathrm{~m}$ a.g.l. (6000 $\mathrm{m}$ a.s.1.) as well as at BOA and compared the non-spherical simulations to the ones calculated via Mie theory. These computations were performed for our five cases of size equivalence VEQV, SEQV, VSEQV, LAEQV and SAEQV.

An effective alternative approach to describe scattering and absorption by non-spherical particles is to represent each model particle by a collection of independent spheres (Grenfell and Warren, 1999). Given a particle of the 'size' $D_{p}$ it is approximated by a number of spheres $N_{s}$ which all have the same diameter $D_{s} . N_{s}$ and $D_{s}$ are determined assuming that the total volume of the spheres as well as their total surface area are same as in the case of the original non-spherical particle. However, this method does not prevent that one has to specify what 'size' $D_{p}$ shall be. Thus, in general one can define such ensembles of independent spheres in each case of size equivalence. For an assumed spheroidal model particle having the aspect ratio $\epsilon$ and considering our five cases of VEQV, SEQV, VSEQV, LAEQV and SAEQV as used above, one can calculate that

(i) $D_{s}=2 D_{p} \epsilon^{\frac{4}{3}} f_{s}(\epsilon)^{-1}$

(ii) $D_{s}=2 D_{p} \epsilon^{2}\left[\frac{1}{2} f_{s}(\epsilon)^{3}\right]^{-\frac{1}{2}}$

(iii) $D_{s}=D_{p}$

(iv) $D_{s}=D_{p} \frac{\epsilon^{2}}{f_{s}(\epsilon)}$ (prolates), $D_{s}=D_{p} \frac{\epsilon}{f_{s}(\epsilon)}$ (oblates).

(v) $D_{s}=D_{p} \frac{\epsilon}{f_{s}(\epsilon)}$ (prolates), $D_{s}=D_{p} \frac{\epsilon^{2}}{f_{s}(\epsilon)}$ (oblates).

where $f_{s}$ is the shape factor of eq. (7). The number of spheres $N_{s}$ does not depend on size equivalence. It is just a function of the AR. The same was reported by Neshyba et al. (2003) for hexagonal columns and plates. We found

$N_{s}=\frac{1}{8} \frac{f_{s}(\epsilon)^{3}}{\epsilon^{4}}$

for spheroids. Since the assumption of volume equivalence, assuming an effective aspect ratio of $\epsilon=1.6$, was found to match our sun photometer and lidar observations best (Section 5.2), we considered VEQV in conjunction with the previously described representation of spheres and hereafter refer to this method by the notation VEQV+GW.

Figure 17(b-f) presents spherical-spheroidal deviations in the irradiances for the downward (blue) and upward (red) transported radiation at the three altitudes. First, one can conclude that the downwelling radiative transfer is mainly affected at BOA by the non-spherical particles in all equivalence cases. Second, large effects occur in the upwelling flux densities around $500 \mathrm{~nm}$ where most of the solar radiation is transported. The even larger relative deviations within the water-vapour absorption bands should not be overrated, since here the total amounts of the transferred energy are close to zero. Third, the non-sphericity effects are larger directly above the dust plume than at TOA. Fourth, the cases VEQV, SEQV and VSEQV show similar results, while these are significantly different to those obtained by LAEQV and SAEQV as expected with regard to the discussions above.

The assumption of VEQV leads to positive deviations in the upward transported radiation around $500 \mathrm{~nm}$ compared to Mie theory, with up to $+10 \%$ directly above the dust plume and $+5 \%$ at TOA. The mean effects at longer wavelengths, except for the regions of strong water-vapour absorption, amount to about $\sim 3 \%$. Since the downwelling radiation at BOA is decreased due to the non-sphericity, the upwelling irradiances at the surface are reduced, too, that is, by the same portion of $\sim 1-3 \%$.

Figure 17(g) depicts the irradiance spectra as in (a) but for the volume equivalent oblate spheroids which now serve as reference case for the verification of the method VEQV+GW whose 

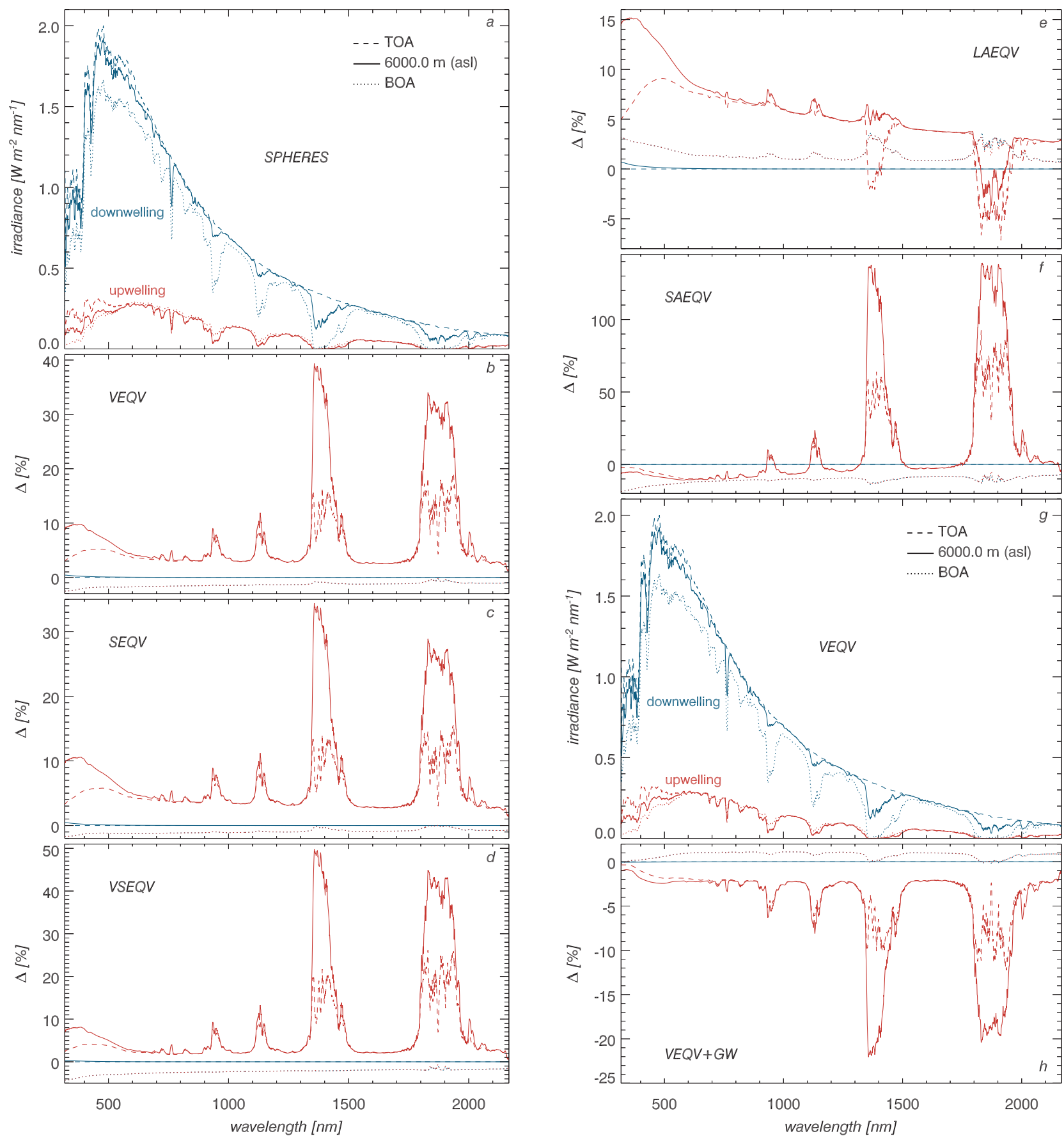

Fig. 17. (a) Upwelling and downwelling spectral irradiances on 19 May over OZT at 12:00 UTC (analogous to Fig. 11) simulated at TOA (dashed), at $4850 \mathrm{~m}$ a.g.1. (6000 $\mathrm{m}$ a.s.l., solid) directly above the dust plume as well as at BOA (dotted) assuming spherical particle shapes. (b-f) Deviations from these Mie-based irradiances taking oblate spheroids with an axis ratio of 1:1.6 $(\epsilon=1.6)$ into account and considering the cases of VEQV, SEQV, VSEQV, LAEQV and SAEQV. (g) As in (a) but considering volume equivalent oblate spheroids $(\epsilon=1.6)$ instead of spheres. (h) Deviations of the method VEQV+GW from the results of $(\mathrm{g})$.

deviations to the reference case VEQV are shown in the lower plate (h). Obviously, one has to state that $\mathrm{VEQV}+\mathrm{GW}$ can mimic non-spherical effects within a mean deviation in the irradiances of about $-2 \%$ neglecting larger differences at regions of strong water-vapour absorption. Therefore, this method indeed is very attractive in the context of flux density calculations including non-spherical aerosols. But note that $\mathrm{VEQV}+\mathrm{GW}$ assumes a number of spherical particles which is larger than originally 
given by measured or adopted size distributions of a considered aerosol population. Moreover, this representation by independent spheres, leading to a LR of 25-29 at $532 \mathrm{~nm}$ depending on altitude, cannot reproduce the measured lidar data, that is, LR of about 48 (Fig. 10, centre).

\section{Atmospheric radiative effects of mineral dust}

To estimate how the non-sphericity of the airborne particles observed in SAMUM's Saharan mineral dust layer can affect the radiation budget of the Earth's atmosphere, we computed various atmospheric radiative effects (AREs) by spectrally integrating the deviations in simulated net radiative flux densities $F_{n}$ of a perturbed reference scenario. $F_{n}$ is defined by $F_{n}\left(x_{3}, \lambda\right):=$ $F_{+}\left(x_{3}, \lambda\right)-F_{-}\left(x_{3}, \lambda\right)$ with the upwelling and downwelling spectral irradiances $F_{+}$as well as $F_{-}$at a certain altitude $x_{3}$. In general one then can write an ARE as

$\Delta F\left(x_{3}\right)=\int_{I_{\lambda}}\left[F_{n}\left(x_{3}, \lambda\right)-F_{n}^{r}\left(x_{3}, \lambda\right)\right] d \lambda$

where $F_{n}$ denotes the perturbed as well as $F_{n}^{r}$ the reference scenario. $I_{\lambda}$ is a certain spectral region. Generally it covers the short-wave range from 0.2 to $4 \mu \mathrm{m}$ wavelength and the longwave from 4 to $\sim 40 \mu \mathrm{m}$. Here we only considered the solar spectral region from 318 to $2167 \mathrm{~nm}$ according to the available measured input data and the discussions above. However, most of the incoming solar radiation is transported within this spectral region. Thus, our calculations of the AREs can be treated to be representative for the short-wave range.

At TOA eq. (8) leads to

$\Delta F(T O A)=\int_{I_{\lambda}}\left[F_{+}(T O A, \lambda)-F_{+}^{r}(T O A, \lambda)\right] d \lambda$,

if the amount of the incoming solar radiation is equal for both scenarios as we assume in the following. This ARE is representative for the radiation loss of the entire Earth-atmosphere system (EAS).

With regard to the commonly used concept of 'radiative forcing' we calculated the ARE at a mean altitude of the tropopause of $12 \mathrm{~km}$ a.s.l. Since this case did not lead to significantly different results as obtained at TOA, we computed the ARE $\Delta F(D)$ at an altitude of $6 \mathrm{~km}$ a.s.l. directly above the mineral dust plume analogously to Fig. 17.

At BOA eq. (8) would result in

$\Delta F=\int_{I_{\lambda}}\left[(1-A(\lambda)) F_{-}(B O A, \lambda)-\left(1-A^{r}(\lambda)\right) F_{-}^{r}(B O A, \lambda)\right] d \lambda$

where $A$ and $A^{r}$ are the spectral surface albedos of the two considered scenarios. However, here we wish to investigate only the changes in the downwelling radiation as a measurement instrument would observe. Thus, we define our ARE at BOA by

$\Delta F(B O A)=\int_{I_{\lambda}}\left[F_{-}(B O A, \lambda)-F_{-}^{r}(B O A, \lambda)\right] d \lambda$.

All AREs were calculated in units of $\mathrm{W} \mathrm{m}^{-2}$. We considered two cases: the measured mineral dust (Fig. 2) over the desert in an atmosphere between 1.15 and $70 \mathrm{~km}$ altitude a.s.l. according to the scenario on 19 May over OZT at 12:00 UTC as discussed above, as well as over ocean in a standard atmosphere from 0 to $70 \mathrm{~km}$. The dust layers adopted were always at the same altitude range from 1.15 to $5.6 \mathrm{~km}$ a.s.l. While in the desert scenario the dust is extended down to the surface, in the ocean case the plume is lifted as during long-range transport. As reference cases we assumed clear-sky atmospheres: Over desert this was the tropical standard atmosphere replaced by the measured profiles (Fig. 3), whereas over ocean the unchanged tropical profiles were used. The reference simulations include only the absorbing gases and the Rayleigh scattering air molecules (Nicolet, 1984). The respective spectral surface albedos were taken from Fig. 8 (bottom). Note that these AREs are to be understood as local effects.

The AREs $\triangle F(T O A), \Delta F(D)$ as well as $\triangle F(B O A)$ were computed, assuming spheroids instead of spheres and considering VEQV, SEQV, VSEQV, SAEQV as well as LAEQV, always a function of the same AR with respect to all model particles. Figure 18 depicts the results and demonstrates that the AREs at TOA and directly above the dust plumes differ only slightly. On the other hand, the AREs show significant differences between our cases of spherical equivalence which are larger at BOA than at TOA. Thus, the interpretation of 'size' with respect to nonspherical particles in a dust ensemble considered can lead to strongly different values of the ARE.

Figure 18 (bottom) shows that the downwelling radiation at BOA is decreased in all cases if the dust is present. It cools the surface. For the cases VEQV, VSEQV and SAEQV an increased non-sphericity enhances this surface cooling due to the forced backscattering with increasing axis ratio, and vice versa for SEQV and LAEQV. Most of these characteristics are more dominant for oblate than for prolate particles, since the former show a stronger backscattering behaviour. At BOA the cooling effect by the dust is always larger over the desert than over the ocean.

The top graph of Fig. 18 shows the radiation loss of the EAS. The Mie calculations (black symbols) indicate that, if the dust is added to the clear atmosphere, this results in a $\triangle F(T O A)$ of $-24 \mathrm{~W} \mathrm{~m}^{-2}$ over desert but of about $+6 \mathrm{~W} \mathrm{~m}^{-2}$ over ocean. As is commonly known, Saharan mineral dust leads to a cooling of the EAS over ocean, but to a warming over land. However, the non-sphericity of its particles can have a big influence on these AREs. This particle property causes enhanced backscattering of radiation over the two surfaces for VEQV, SEQV, VSEQV as well as LAEQV: The AREs are always larger than in the Mie case, that is, for ARs non equal to unity. Again, oblate 


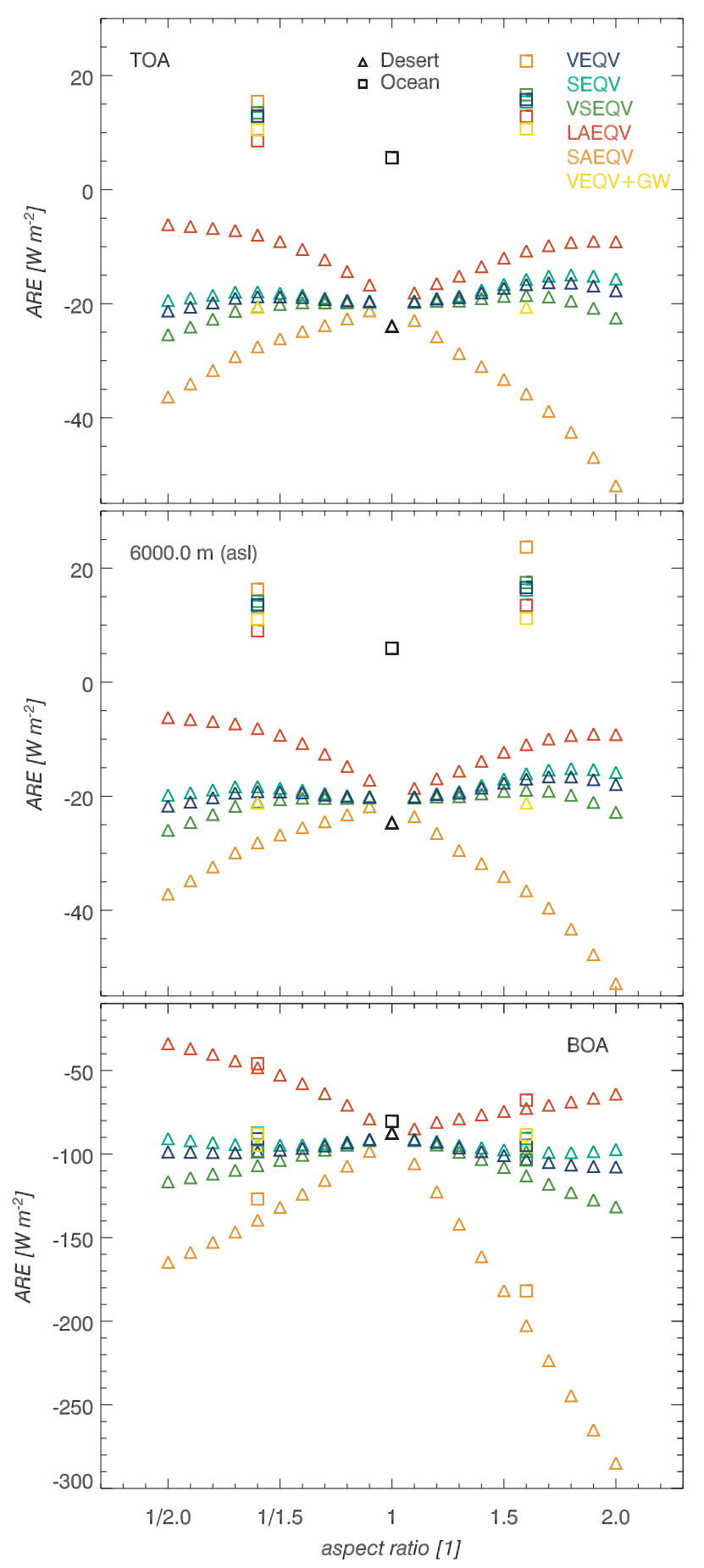

Fig. 18. Atmospheric radiative effects (AREs) of SAMUM's Saharan mineral dust measured on 19 May over desert (triangle) and ocean (squares) as function of the aspect ratio (AR) for assumed prolate (ARs lower than 1.0) and oblate (larger than 1.0) spheroidal model particles considering the equivalence cases VEQV (blue), SEQV (light green), VSEQV (dark green), LAEQV (red), SAEQV (orange) and $\mathrm{VEQV}+\mathrm{GW}$ (yellow). For details see the main text. (top panel) $\triangle F(T O A)$. (centre panel) $\Delta F(D)$. (bottom panel) $\Delta F(B O A)$; All simulations were performed for a local SZA of $\sim 12.5^{\circ}$ as in Fig. 11 . dust particles force these backscattering effects leading to larger values of $\triangle F(T O A)$ than obtained by prolate shapes for the rather realistic cases of VEQV, SEQV and VSEQV to describe the non-sphericity of mineral dust particles.

In the following, we consider the case of VEQV: For an assumed oblate aerosol population with an effective axis ratio of 1:1.6 ( $\mathrm{AR} \epsilon=1.6$ ), probably most representative for the mineral dust measured on 19 May during SAMUM as discussed above, $\triangle F(T O A)$ amounts to about $-17 \mathrm{~W} \mathrm{~m}^{-2}$ over desert and $+16 \mathrm{~W} \mathrm{~m}^{-2}$ over ocean (the respective values obtained by VEQV $+\mathrm{GW}$ are significantly lower with $-21 \mathrm{~W} \mathrm{~m}^{-2}$ over desert and $+11 \mathrm{~W} \mathrm{~m}^{-2}$ over ocean). These data indicate that the non-sphericity of dust particles can lead to solar atmospheric radiative effects at TOA enhanced by $29 \%$ (VEQV+GW: $13 \%)$ over the desert as well as by $167 \%(83 \%)$ over the ocean. At TOA the warming effect of a larger surface albedo, as in the case of the desert, is counteracted by the cooling effect of the non-sphericity. The AREs of the method VEQV+GW at TOA compared to VEQV also indicate that this elegant approach can mimic effects of non-spherical particles, however, unfortunately it explains merely $\sim 50 \%$ of their impact.

Bierwirth et al. (2008) considered the same dust plume on 19 May, as in Fig. 18, but for a solar zenith angle of $12.0^{\circ}$, to calculate the solar ARE at TOA over the same desert surface by applying measured data of the optical depth and single scattering albedo (SSA). However, at $537 \mathrm{~nm}$ a SSA of $\omega_{o}(0.537)$ $=0.95$ was assumed, as calculated via Mie theory by Schladitz et al. (2008) based on measured particle data restricted to smaller particles. For this SSA Bierwirth et al. (2008) found an ARE of $-3 \mathrm{~W} \mathrm{~m}^{-2}$ which is larger than our value of $-24 \mathrm{~W} \mathrm{~m}^{-2}$ for a SSA of 0.8 at $550 \mathrm{~nm}$ (Fig. 10, bottom) in the case of spherical particles. In addition, these authors considered also the cases in which the SSA was reduced to $\omega_{o}(0.55)=0.87$ as well as increased to $\omega_{o}(0.55)=1.0$, that is, $\pm 10 \%$, and computed AREs of about $-17 \mathrm{~W} \mathrm{~m}^{-2}$ and $+6 \mathrm{~W} \mathrm{~m}^{-2}$, respectively. This demonstrates how strong the ARE of mineral dust is influenced by a SSA which can have values lower than 0.95 if large dust particles are present. The ARE of $+6 \mathrm{~W} \mathrm{~m}^{-2}$ indicates that a non-absorbing dust $\left(\omega_{o}(0.55)=1.0\right)$ can also lead to a cooling over the relatively strong reflecting desert, while the $-17 \mathrm{~W} \mathrm{~m}^{-2}$ for a stronger absorbing dust $\left(\omega_{o}(0.55)=0.87\right)$ can result in an enhanced warming. Interestingly, the latter value is the same as we obtained in the case of non-spherical dust particles over the desert surface but for our even more absorbing dust $\left(\omega_{o}(0.55)=0.8\right)$. Thus, for a certain spectral surface albedo the non-consideration of the non-sphericity of the dust particles can lead to misinterpretations of their absorbing properties. Therefore, satellite-based retrievals of mineral dust, taking observations of the backscattered radiation as input, have to account for such effects of the particle non-sphericity as well as the presence of coarse mode particles. Otherwise, the derived values of $\omega_{o}$ at solar wavelengths might be overestimated. 


\section{Conclusions}

The solar optical properties and radiative effects of a Saharan mineral dust plume observed during SAMUM were studied based on measured size-number distributions and chemical composition of the dust. The latter were utilised to estimate the size-resolved complex refractive index which was then applied to calculate the dust optical properties. Our results for the single scattering albedo indicate that the Saharan mineral dust may be more absorbing than currently supposed, mainly caused by large particles.

Simulated backscatter coefficients as well as lidar ratios were compared to independent data measured by various lidars. It turned out that the observed dust particles were definitely of non-spherical shapes. The lidar data were used, together with sun photometer measurements, to estimate the most representative spherical equivalence and an effective shape of the nonspherical particles, assuming model spheroids and considering various cases of size equivalence. Our single scattering simulations demonstrated that volume equivalent oblate spheroids of an effective axis ratio of 1:1.6 led to the best agreement with both the lidar data, the sun photometer observations and the single particle analyses via a scanning electron microscope. To perform the computations, a database of monodisperse optical properties for spheroidal particles was constructed which also was applied to compute the non-spherical radiative effects of the dust. Irradiance simulations in the solar range demonstrated that the downwelling radiation is less influenced by the nonsphericity of the particles than the upward transport which is significantly affected: the non-sphericity leads to enhanced cooling of the Earth-atmosphere system within the solar region due to forced backscattering by the dust particles. Thus, downwardslooking radiation measurements in this spectral range should be performed directly above a dust plume to fully capture their non-spherical effects.

Although distributions of the aspect ratio with respect to particle size were measured during the SAMUM campaign, in our considerations of particle non-sphericity we always assumed model spheroids to have constant aspect ratios, and interpreted them as effective ARs which are representative of the entire particle ensemble and which match the independent SAMUM measurements best. However, we note that the ensemble-averaged optical properties are in general surjective functions of their input quantities, that is, various combinations of the latter may produce the same results for the former, or the inversion of shape information from ensemble data of the optical properties does not have to be unique. Thus, the fixed effective axis ratio derived from our lidar and sun photometer observations might be one solution, and the use of measured as well as theoretical distributions of the aspect ratio with regard to our insitu measurements may be interesting to discuss in a following paper.
We considered various idealised cases of size equivalence. It turned out that experimental information on the term 'size', in the context of the interpretation of size measurements of irregularly shaped dust particles, is essential for satisfactory modelling of the optical properties and radiative effects of mineral dust. Moreover, these considerations of spherical equivalence might also be inspiring for studies concerning further types of non-spherical aerosol particles or cloud elements.

Measured vertical profiles of the total number concentration together with an extended number of size distribution measurements at different levels would significantly improve the simulation of the vertical dependence of the spectral optical properties and vertically transported radiation. Measurements of more detailed height-resolved information about the chemical composition and shape of the particles might also be of interest in order to distinguish various aerosol types contained in observed layered aerosol plumes, which would also simplify their modelling. Aircraft-based measurements of the (large) dust particles and the chemical composition over wide horizontal distances might extend the information about dust optical properties and radiative effects during long-range transports.

The particles of the observed Saharan mineral dust plume were non-spherical. The dust population also contained a significant fraction of coarse particles. Both have a strong impact on the absorption and backscattering properties of dust, and thus need to be considered in satellite-based retrievals.

Again, we emphasise the need for more detailed data of the complex refractive index with regard to major constituents of mineral dust and spectral cover in order to minimise the uncertainties with respect to this quantity which can lead to radiative effects of the same order of magnitude as caused by the large particles or the particle shape.

This paper reported merely on spectral optical properties and radiative effects of non-spherical mineral dust particles within the solar spectral range. Respective considerations with regard to wavelengths in the thermal infrared will be one of our future research topics.

\section{Acknowledgments}

The presented study was supported and funded by the German Research Foundation (DFG) within the Research Group SAMUM. The first author thanks all field scientists within SAMUM for providing their precious measurement data. He is very grateful to his colleagues at DLR IMF-AP who allowed him to 'grid' engross their computers for the time-consuming scattering computations during the last two years. He thanks also S. Krischke, S. Thuß and C. McConnell for intensive reading of the manuscript. Special thanks go to M. Mishchenko, P. Yang and A. Macke for the possibility to use their scattering codes. The authors are also very grateful to the reviewers for their critical but fair as well as useful comments to top off the paper. 


\section{References}

d'Almeida, G. A., Koepke, P. and Shettle, E. P. 1991. Atmospheric Aerosols: Global Climatology and Radiative Characteristics. A. Deepak Publishing, Hampton, Virginia, USA, 561 pp.

Althausen, D., Müller, D., Ansmann, A., Wandinger, U., Hube, H. and co-authors. 2000. Scanning 6-wavelength 11-channel aerosol lidar. $J$. Atmos. Ocean. Technol. 17, 1469-1482.

Anderson, G. P., Clough, S. A., Kneiyzs, F. X., Chetwynd, J. H. and Shettle, E. P. 1986. AFGL Atmospheric constituent profiles (0-120 km). AFGL-TR-86-0110, AFGL (OPI), Hanscom AFB, MA 01736.

Ansmann, A., Tesche, M., Knippertz, P., Bierwirth, E., Althausen, D. and co-authors. 2008. Vertical profiling of convective dust plumes in southern Morocco during SAMUM. Tellus 61B, doi:10.1111/j.16000889.2008.00384.x.

Arakawa, E. T., Tuminello, P. S., Khara, B. N., Millham, M. E., Authier, S. and co-authors. 1997. Measurement of optical properties of small particles. NASA Ames Research Center, pages Report Number: CONF9706222, DE98001913, ORNL CP95872.

Aronson, J. R., Emslie, A. G., Miseo, E. V., Smith, E. M. and Strong, P. F. 1983. Optical constants of monoclinic anisotropic crystals: gypsum. Appl. Opt. 22, 4093-4098.

Balkanski, Y., Schulz, M., Claquin, T. and Guibert, S. 2007. Reevaluation of mineral aerosol radiative forcings suggests a better agreement with satellite and AERONET data. Atmos. Chem. Phys. 7, 81-95.

Bass, A. M. and Paur, R. J. 1981. UV absorption cross-sections for ozone: the temperature dependence. J. Photochem. 17, 141.

Bedidi, A. and Cervelle, B. 1993. Light scattering by spherical particles with hematite- and goethite-like optical properties. Effect of water impregnation. J. Geophys. Res. 98, 11 941-11952.

Bierwirth, E., Wendisch, M., Ehrlich, A., Heese, B., Tesche, M. and coauthors. 2008. Spectral surface albedo over Morocco and its impact on the radiative forcing of Saharan dust. Tellus 61B, doi:10.1111/j.16000889.2008.00395.x.

Bogumil, K., Orphal, J. and Burrows, J. P. 2000. Temperature dependent absorption cross sections of $\mathrm{O}_{3}, \mathrm{NO}_{2}$, and other atmospheric trace gases measured with the SCIAMACHY spectrometer. Proceedings of the ERS - Envisat - Symposium. Looking down at our Earth in the New Millennium, Goteburg, Sweden, 2000.

Burrows, J. P., Dehn, A., Deters, B., Himmelmann, S., Richter, A. and co-authors. 1998. Atmospheric remote-sensing reference data from GOME: 1. Temperature-dependent absorption cross sections of $\mathrm{NO}_{2}$ in the 231-794 nm range. J. Quant. Spectrosc. Radiat. Transfer 60, $1025-1031$.

Burrows, J. P., Dehn, A., Deters, B., Himmelmann, S., Richter, A. and co-authors. 1999. Atmospheric remote-sensing reference data from GOME: 2. Temperature-dependent absorption cross sections of $\mathrm{O}_{3}$ in the 231-794 nm range. J. Quant. Spectrosc. Radiat. Transfer 61, 509-517.

Cantrell, C. A., Davidson, J. A., McDaniel, A. J., Shetter, R. E. and Calvert, J. G. 1990. Temperature-dependent formaldehyde cross sections in the near-ultraviolet spectral region. J. Phys. Chem. 94, 39023908.

Carlson, T. N. and Benjamin, S. G. 1980. Radiative heating rates for Saharan dust. Am. Meteor. Soc. 37, 193-213.

Carlson, T. N. and Caverly, R. S. 1977. Radiative characteristics of Saharan dust at solar wavelengths. J. Geophys. Res. 82, 31413152 .
Cattrall, C., Carder, K. L. and Gordon, H. R. 2003. Columnar aerosol single-scattering albedo and phase function retrieved from sky radiance over the ocean: measurements of Saharan dust. J. Geophys. Res. 108(D9), 4287, doi:10.1029/2002JD002497.

Collins, D. R., Jonsson, H. H., Seinfeld, J. H., Flagan, R. C., Gassó, S. and co-authors. 2000. In situ aerosol-size distributions and clearcolumn radiative closure during ACE-2. Tellus 52B, 498-525.

Collins, W. D., Lee-Taylor, J. M., Edwards, D. P. and Francis, G. L. 2006. Effects of increased near-infrared absorption by water vapor on the climate system. J. Geophys. Res. 111, D18109, doi:10.1029/2005JD006796.

Dubovik, O., Holben, B. N., Eck, T. F., Smirnov, A., Kaufman, Y. J. and co-authors. 2002a. Variability of absorption and optical properties of key aerosol types observed in worldwide locations. J. Atmos. Sci. 59, 590-608.

Dubovik, O., Holben, B. N., Lapyonok, T., Sinyuk, A., Mishchenko, M. I. and co-authors. 2002b. Non-spherical aerosol retrieval method employing light scattering by spheroids. Geophys. Res. Lett. 29(10), doi:10.1029/2001GL014506.

Dubovik, O., Sinyuk, A., Lapyonok, T., Holben, B. N., Mishchenko, M. and co-authors. 2006. Application of spheroid models to account for aerosol particle nonsphericity in remote sensing of desert dust. $J$. Geophys. Res. 111, D11208, doi:10.1029/2005JD006619.

Egan, W. G. and Hilgeman, T. W. 1979. Optical Properties of Inhomogeneous Materials: Applications to Geology, Astronomy, Chemistry, and Engineering. Academic Press, San Diego, California, 235 pp.

Esselborn, M., Wirth, M., Fix, A., Tesche, M. and Ehret, G. 2008a. Airborne high spectral resolution lidar for measuring aerosol extinction and backscatter coefficients. Appl. Opt. 47(3), 346-358.

Esselborn, M., Wirth, M., Fix, A., Weinzierl, B., Rasp, K. and co-authors. 2008b. Spatial distribution and optical properties of Saharan dust observed by airborne high spectral resolution lidar during SAMUM 2006. Tellus 61B, doi:10.1111/j.1600-0889.2008.00394.x.

Falkovich, A. H., Ganor, E., Levin, Z., Formenti, P. and Rudich, Y. 2001. Chemical and mineralogical analysis of individual mineral dust particles. J. Geophys. Res. 106(D16), 18 029-18036.

Fleischmann, O. C., Hartmann, M., Burrows, J. P. and Orphal, J. 2004. New ultraviolet absorption cross-sections of $\mathrm{BrO}$ at atmospheric temperatures measured by time-windowing Fourier transform spectroscopy. J. Photochem. Photobiol. A: Chem. 168, 117-132.

Formenti, P., Andreae, M. O. and Lelieveld, J. 2000. Measurements of aerosol optical depth above $3570 \mathrm{~m}$ asl in the North Atlantic free troposphere: results from ACE-2. Tellus 52B, 678-693.

Fouquart, Y., Bonnel, B., Brogniez, G., Buriez, J. C., Smith, L. and coauthors. 1987. Observations of Saharan aerosols: Results of ECLATS field experiment, Part II: Broadband radiative characteristics of the aerosols and vertical radiative flux divergence. J. Clim. Appl. Met. 26, 38-52.

Freeman, D. E., Yoshino, K., Esmond, J. R. and Parkinson, W. H. 1984. High resolution absorption cross section measurements of $\mathrm{SO}_{2}$ at $213 \mathrm{~K}$ in the wavelength region $172-240 \mathrm{~nm}$. Planet. Space. Sci. 32, 1125-1134.

Gillespie, J. B. and Lindberg, J. D. 1992. Ultraviolet and visible imaginary refractive index of strongly absorbing atmospheric particulate matter. Appl. Opt. 31, 2112-2115.

Glotch, T. D., Rossman, G. R. and Aharonson, O. 2007. Mid-infrared (5 $100 \mu \mathrm{m})$ reflectance spectra and optical constants of ten phyllosilicate minerals. Icarus 192, doi:10.1016/j.icarus.2007.07.02, 605-622. 
Grenfell, T. C. and Warren, S. G. 1999. Representation of a nonspherical ice particle by a collection of independent spheres for scattering and absorption of radiation. J. Geophys. Res. 104(D24), 31 697-31 709 .

Grenfell, T. C., Neshyba, S. P. and Warren, S. G. 2005. Representation of a nonspherical ice particle by a collection of independent spheres for scattering and absorption of radiation: 3 . Hollow columns and plates. J. Geophys. Res. 110, D17203, doi:10.1029/2005JD005811.

Haywood, J., Francis, P., Osborne, S., Glew, M., Loeb, N. and co-authors. 2003. Radiative properties and direct radiative effect of Saharan dust measured by the C-130 aircraft during SHADE: 1 . Solar spectrum. $J$. Geophys. Res. 108(D18), 8577, doi:10.1029/2002JD002687.

Heintzenberg, J. 2008. The SAMUM-1 experiment over Southern Morocco: overview and introduction. Tellus 61B, doi:10.1111/j.16000889.2008.00403.x.

Henning, T., Mutschke, H. and Dorschner, J. 1995. Optical properties of oxide dust grains. Astron. Astrophys. Suppl. Ser. 112, 143149.

Henning, T. and Mutschke, H. 1997. Low-temperature infrared properties of cosmic dust analogues. Astron. Astrophys. 327, 743754.

Hess, M., Koepke, P. and Schult, I. 1998. Optical Properties of Aerosols and clouds: the software package OPAC. Bull. Am. Met. Soc. 79(7), 831-844.

von Hoyningen-Huene, W. and Posse, P. 1997. Nonsphericity of aerosol particles and their contribution to radiative forcing. J. Quant. Spectrosc. Radiat. Transfer 57(5), 651-668.

Hsu, W. P. and Matijevic, E. 1985. Optical properties of monodispersed hematite hydrosols. Appl. Opt. 24, 1623-1629.

Ivlev, L. S. and Andreev, S. D. 1986. Optical properties of atmospheric aerosols. Gidrometeoizdat, Leningrad (in Russian).

Ivlev, L. S. and Popova, S. I. 1972. Optical constants of substances of atmospheric aerosols. Izv. Vys. Uch. Zav. Fiz. 5, 91-97.

Jacobson, M. Z. 2000. A physically-based treatment of elemental carbon optics: implications for global direct forcing of aerosols. Geophys. Res. Lett. 27(2), 217-220.

Jarzembski, M. A., Norman, M. L., Fuller, K. L., Srivastava, V. and Cutton, D. R. 2003. Complex refractive index of ammonium nitrate in the 2 - $20 \mu m$ spectral range. Appl. Opt. 42, 922-930.

Kahnert, M. and Kylling, A. 2004. Radiance and flux simulations for mineral dust aerosols: assessing the error due to using spherical or spheroidal model particles. J. Geophys. Res. 109, D09203, doi:10.1029/2003JD004318.

Kahnert, M. 2004. Reproducing the optical properties of fine desert dust aerosols using ensembles of simple model particles. J. Quant. Spectrosc. Radiat. Transfer 85, 231-249.

Kahnert, M., Nousiainen, T. and Veihelmann, B. 2005. Spherical and spheroidal model particles as an error source in aerosol climate forcing and radiance computations: a case study for feldspar aerosols. $J$. Geophys. Res. 110, D18S13, doi:10.1029/2004JD005558.

Kahnert, M., Nousiainen, T. and Räisänen, P. 2007. Mie simulations as an error source in mineral dust aerosol radiative forcing calculations. Q. J. R. Meteorol. Soc. 133, 299-307.

Kandler, K., Schütz, L., Deutscher, C., Ebert, M., Hofmann, H. and coauthors. 2008. Size distribution, mass concentration, chemical and mineralogical composition, and derived optical parameters of the boundary layer aerosol at Tinfou, Morocco, during SAMUM 2006. Tellus 61B, doi:10.1111/j.1600-0889.2008.00385.x.
Kaufman, Y. J., Tanré, D., Dubovik, O., Karnieli, A. and Remer, L. A. 2001. Absorption of sunlight by dust as inferred from satellite and ground-based remote sensing. Geophys. Res. Lett. 28(8), 1479-1482.

Koven, C. D. and Fung, I. 2006. Inferring dust composition from wavelength-dependent absorption in Aerosol Robotic Network (AERONET) data. J. Geophys. Res. 111, D14205, doi:10.1029/2005JD006678.

Kromminga, H., Orphal, J., Spietz, P., Voigt, S. and Burrows, J. P. 2003. The temperature dependence (213-293 K) of the absorption crosssections of $\mathrm{OClO}$ in the $340-450 \mathrm{~nm}$ region measured by Fouriertransform spectroscopy. J. Photochem. Photobiol. A: Chem. 157, 149160.

Lafon, S., Sokolik, I. N., Rajot, J. L., Caquineau, S. and Gaudichet, A. 2006. Characterization of iron oxids in mineral dust aerosols: implications for light absorption. J. Geophys. Res. 111, D21207, doi:10.1029/2005JD007016.

Levin, Z., Joseph, J. H. and Mekler, Y. 1980. Properties of Sharav (Khamsin) dust—comparison of optical and direct sampling data. $J$. Atmos. Sci. 37, 882-891.

Lindberg, J. D. and Laude, L. S. 1974. Measurements of the absorption coefficient of atmospheric dust. Appl. Opt. 13, 1923-1927.

Lindberg, J. D. 1975. The composition and optical absorption coefficient of atmospheric particulate matter. Optic. Quant. Electron. 7, 131-139.

Lindberg, J. D. and Gillespie, J. B. 1977. Relationship between particle size and imaginary index in atmospheric dust. Appl. Opt. 16(10), 2628-2630.

Linke, C., Möhler, O., Veres, A., Mohácsi, Á., Bozóki, Z. and co-authors. 2006. Optical properties and mineralogical composition of different Saharan mineral dust samples: a laboratory study. Atmos. Chem. Phys. 6, 3315-3323.

Long, L. L., Querry, M. R., Bell, R. J. and Alexander, R. W. 1993. Optical properties of calcite and gypsum in chrystalline and powdered form in the infrared and far-infrared. Infrared Phys. 34, 191-201.

Macke, A. and Mishchenko, M. I. 1996. Applicability of regular particle shapes in light scattering calculations for atmospheric ice particles. Appl. Opt. 35, 4291-4296.

Markowicz, K. M., Flatau, P. J., Vogelmann, A. M., Quinn, P. K. and Welton, E. J. 2003. Clear-sky infrared aerosol radiative forcing at the surface and the top of the atmosphere. Q. J. R. Meteorol. Soc. 129, 2927-2947.

Marra, A. C., Blanco, A., Fonti, S., Jurewicz, A. and Orofino, V. 2005. Fine hematite particles of Martian interest: absorption spectra and optical constants. J. Phys.: Conference Series 6, doi:10.1088/17426596/6/1/013, 132-138.

Mishchenko, M. I. 1991. Light scattering by randomly oriented axially symmetric particles. J. Opt. Soc. Am. A8, 871-882.

Mishchenko, M. I. 1993. Light scattering by size-shape distributions of randomly oriented axially symmetric particles of a size comparable to a wavelength. Appl. Opt. 32, 4652-4666.

Mishchenko, M. I. and Travis, L. D. 1994a. T-matrix computations of light scattering by large spheroidal particles. Opt. Commun. 109, 1621.

Mishchenko, M. I. and Travis, L. D. 1994b. Light scattering by polydispersions of randomly oriented spheroids with sizes comparable to a wavelength. Appl. Opt. 33, 7206-7225.

Mishchenko, M. I., Travis, L. D. and Mackowski, D. W. 1996. T-matrix computations of light scattering by nonspherical particles: a review. J. Quant. Spectrosc. Radiat. Transfer 55, 535-575. 
Mishchenko, M. I., Travis, L. D., Kahn, R. A. and West, R. A. 1997. Modeling phase functions for dustlike tropospheric aerosols using a shape mixture of randomly oriented polydisperse spheroids. J. Geophys. Res. 102(D14), 16831-1687.

Mishchenko, M. I. and Travis, L. D. 1998. Capabilities and limitations of a current FORTRAN implementation of the T-matrix method for randomly oriented, rotationally symmetric scatterers. J. Quant. Spectrosc. Radiat. Transfer 60, 309-324.

Mogili, P. K., Yang, K. H., Young, M. A., Kleiber, P. D. and Grassian, V. H. 2007. Environmental aerosol chamber studies of extinction spectra of mineral dust aerosol components: broadband IRUV extinction spectra. J. Geophys. Res. 112, D21204, doi:10.1029/2007JD008890.

Molina, L. T. and Molina, M. J. 1986. Absolute absorption cross sections of ozone in the 185- to 350-nm wavelength range. J. Geophys. Res. 91, 14 501-14508.

Mooney, T. and Knacke, R. F. 1985. Optical constants of chlorite and serpentine between 2.5 and $50 \mu \mathrm{m}$. Icarus 64, 493-502.

Müller, T., Schladitz, A., Massling, A., Kaaden, N., Wiedensohler, A. and co-authors. 2008. Spectral absorption coefficients and imaginary parts of refractive indices of Saharan dust during SAMUM-1. Tellus 61B, doi:10.1111/j.1600-0889.2008.00399.x.

Myhre, G. and Stordal, F. 2001. Global sensitivity experiments of the radiative forcing due to mineral aerosols. J. Geophys. Res. 106(D16), 18 193-18 204.

Neshyba, S. P., Grenfell, T. C. and Warren, S. G. 2003. Representation of a nonspherical ice particle by a collection of independent spheres for scattering and absorption of radiation: 2. Hexagonal columns and plates. J. Geophys. Res. 108(D15), 4448, doi:10.1029/2002JD003302.

Nicolet, M. 1984. On the molecular scattering in the terrestrial atmosphere: an empirical formula for its calculation in the homosphere. Planet. Space Sci. 32, 1467-1468.

Nousiainen, T. and Vermeulen, K. 2003. Comparison of measured singlescattering matrix of feldspar particles with T-matrix simulations using spheroids. J. Quant. Spectrosc. Radiat. Transfer 79-80, 10311042.

Nousiainen, T., Kahnert, M. and Veihelmann, B. 2006. Light scattering modeling of feldspar aerosol particles using polyhedral prisms and spheroids. J. Quant. Spectrosc. Radiat. Transfer 101, 471-487.

Olmo, F. J., Quirantes, A., Lara, V., Lyamani, H. and Alados-Arboledas, L. 2008. Aerosol optical properties assessed by an inversion method using the solar principal plane for non-spherical particles. J. Quant. Spectrosc. Radiat. Transfer 109, 1504-1516.

Orphal, J., Fellows, C. E. and Flaud, P.-M. 2003. The visible absorption spectrum of $\mathrm{NO}_{3}$ measured by high-resolution Fourier-transform spectroscopy. J. Geophys. Res. 108(D3), doi:10.1029/2002JD002489.

Osborne, S. R., Johnson, B. T., Haywood, J. M., Baran, A. J., Harrison, M. A. J. and co-authors. 2008. Physical and optical properties of mineral dust aerosol during the Dust and Biomassburning Experiment (DABEX). J. Geophys. Res. 113, D00C03, doi:10.1029/2007JD009551.

Otto, S., de Reus, M., Trautmann, T., Thomas, A., Wendisch, M. and co-authors. 2007. Atmospheric radiative effects of an in situ measured Saharan dust plume and the role of large particles. Atmos. Chem. Phys. 7, 4887-4903.

Palmer, K. F. and Williams, D. 1975. Optical constants of sulfuric acid; application to the clouds of Venus? Appl. Opt. 14, 208-219.
Patterson, E. M., Gilette, D. A. and Stockton, B. H. 1977. Complex index of refraction between 300 and $700 \mathrm{~nm}$ for Saharan aerosols. $J$. Geophys. Res. 82, 3153-3160.

Perrone, M. R., Barnaba, F., de Tomasi, F., Gobbi, G. P. and Tafuro, A. M. 2004. Imaginary refractive-index effects on desert-aerosol extinction versus backscatter relationships at $531 \mathrm{~nm}$ : numerical computations and comparison with Raman lidar measurements. Appl. Opt. 43, 5531-5541.

Petzold, A., Rasp, K., Weinzierl, B., Esselborn, M., Hamburger, T. and co-authors. 2008. Saharan dust absorption and refractive index from aircraft-based observations during SAMUM 2006. Tellus 61B, doi:10.1111/j.1600-0889.2008.00383.x.

Philipp, H. R. 1985. Silicon Dioxide ( $\left.\mathrm{SiO}_{2}\right)$, Type $\alpha$ (Crystalline). In: Handbook of Optical Constants of Solids I, (ed. E. D. Palik), Academic Press, New York, 719-747.

Pilinis, C. and Li, X. 1998. Particle shape and internal inhomogeneity effects in the optical properties of tropospheric aerosols of relevance to climate forcing. J. Geophys. Res. 103(D4), 37893800.

Popova, S. I., Tolstykh, T. S. and Vorobev, V. T. 1972. Optical characteristics of amorphous quartz in the $1400-200 \mathrm{~cm}^{-1}$ region. Opt. Spectrosc. 33, 444-445.

Querry, M. R., Osborne, G., Lies, K., Jordan, R. and Coveney, R. M. jr. 1978. Complex refractive index of limestone in the visible and infrared. Appl. Opt. 17, 353-356.

Querry, M. R. 1987. Optical constants of mineral and other materials from millimeter to the UV. Rep. CRDEC-CR-88009, U.S., Aberdeen, MD.

Reid, J. S., Jonsson, H. H., Maring, H. B., Smirnov, A., Savoie, D. L. and co-authors. 2003. Comparison of size and morphological measurements of coarse mode dust particles from Africa. J. Geophys. Res. 108(D19), 8593, doi:10.1029/2002JD002484.

Rother, T., Schmidt, K., Wauer, J., Shcherbakov, V. and Gayet, J.-F. 2006. Light scattering on Chebyshev particles of higher order. Appl. Opt. 45(23), 6030-6037.

Rothman, L. S., Jacquemart, D., Barbe, A., Chris Benner, D., Birk, M. and co-authors. 2005. The HITRAN 2004 molecular spectroscopic database. J. Quant. Spectrosc. Radiat. Transfer 96, 139-204.

Roush, T., Pollack, J. and Orenberg, J. 1991. Derivation of mid-infrared (5 - $25 \mu \mathrm{m}$ ) optical constants of some silicates and palagonite. Icarus 94, 191-208.

Schladitz, A., Müller, T., Kaaden, N., Massling, A., Kandler, K. and co-authors. 2008. In situ measurements of optical properties at Tinfou (Morocco) during the Saharan Mineral Dust Experiment SAMUM 2006. Tellus 61B, doi:10.1111/j.1600-0889.2008.00397.x.

Schmid, B., Livingston, J. M., Russell, P. B., Durkee, P. A., Jonsson, H. H. and co-authors. 2000. Clear-sky closure studies of lower tropospheric aerosol and water vapor during ACE-2 using airborne sunphotometer, airborne in-situ, space-borne, and ground-based measurements. Tellus 52B, 568-593.

Schmid, B., Hegg, D. A., Wang, J., Bates, D., Redemann, J. and coauthors. 2003. Column closure studies of lower tropospheric aerosol and water vapor during ACE-Asia using airborne Sun photometer and airborne in situ and ship-based lidar measurements. J. Geophys. Res. 108(D23), 8656, doi:10.1029/2002JD003361.

Schulz, F. M., Stamnes, K. and Stamnes, J. J. 1999. Shape dependence of the optical properties in size-shape distributions of randomly oriented 
prolate spheroids, including highly elongated shapes. J. Geophys. Res. 104(D8), 9413-9421.

Shettle, E. P. and Fenn, R. W. 1979. Models of the aerosols of the lower atmosphere and the effects of humidity variations on their optical properties. Project 7670, Air Force Geoph. Lab., Massachusetts.

Sokolik, I. N., Andronova, A. and Johnson, T. C. 1993. Complex refractive index of atmospheric dust aerosols. Atmos. Environ. 27A(16), 2495-2502.

Sokolik, I. N. and Toon, O. B. 1999. Incorporation of mineralogical composition into models of the radiative properties of mineral aerosol from UV to IR wavelengths. J. Geophys. Res. 104(D8), 94239444.

Sokolik, I. N., Winker, D. M., Bergametti, G., Gilette, D. A., Carmichael, G. and co-authors. 2001. Introduction to special section: outstanding problems in quantifying the radiative impacts of mineral dust. J. Geophys. Res. 106(D16), $18015-18027$.

Stamnes, K., Tsay, S., Wiscombe, W. and Jayaweera, K. 1988. Numerically stable algorithm for discrete-ordinate-method radiative transfer in multiple scattering and emitting layered media. Appl. Opt. 27, 2502-2509.

Stamnes, K., Tsay, S.-C., Wiscombe, W. and Laszlo, I. 2000. DISORT, a general-purpose fortran program for discrete-ordinate-method radiative transfer in scattering and emitting layered media: documentation of methodology. Tech. Rep., Dept. of Physics and Engineering Physics, Stevens Institute of Technology, Hoboken, NJ 07030.

Steyer, T. R., Day, K. L. and Huffman, D. R. 1974. Infrared absorption by small amorphous quartz spheres. Appl. Opt. 13, 15861590.

Tegen, I. and Lacis, A. A. 1996. Modeling of particle size distribution and its influence on the radiative properties of mineral dust aerosol. J. Geophys. Res. 101(D14), 19237-19244.

Tesche, M., Ansmann, A., Müller, D., Althausen, D., Mattis, I. and coauthors. 2008. Vertical profiling of Saharan dust with Raman lidars and airborne HSRL in southern Morocco during SAMUM. Tellus 61B, doi:10.1111/j.1600-0889.2008.00390.x.

Toon, O. B., Pollack, J. B. and Khare, B. N. 1976. The optical constants of several atmospheric aerosol species: ammonium sulfate, ammonium oxide, and sodium chloride. J. Geophys. Res. 81, 5733-5748.

Tropf, W. J. 1998. Calcium Carbonate, Calcite $\left(\mathrm{CaCO}_{3}\right)$. In: Handbook of Optical Constants of Solids III, (ed. E. D. Palik), Academic Press, New York, 701-715.

Vandaele, A. C., Hermans, C., Simon, P. C., Carleer, M., Colin, R. and co-authors. 1998. Measurements of the $\mathrm{NO}_{2}$ absorption cross-section from $42000 \mathrm{~cm}^{-1}$ to $10000 \mathrm{~cm}^{-1}(238-1000 \mathrm{~nm})$ at $220 \mathrm{~K}$ and 294 K. J. Quant. Spectrosc. Radiat. Transfer 59, 171-184.

Voigt, S., Orphal, J., Bogumil, K. and Burrows, J. P. 2001. The temperature dependence (203-293 K) of the absorption cross sections of $\mathrm{O}_{3}$ in the $230-850 \mathrm{~nm}$ region measured by Fourier-transform spectroscopy. J. Photochem. Photobiol. A: Chem. 143, 1-9.

Voigt, S., Orphal, J. and Burrows, J. P. 2002. The temperature- and pressure-dependence of the absorption cross sections of $\mathrm{NO}_{2}$ in the $250-800 \mathrm{~nm}$ region measured by Fourier-transform spectroscopy. $J$. Photochem. Photobiol. A: Chem. 149, 1-7.
Volten, H., Muñoz, O., Rol, E., de Haan, J. F., Vassen, W. and co-authors. 2001. Scattering matrices of mineral aerosol particles at $441.6 \mathrm{~nm}$ and 632.8 nm. J. Geophys. Res. 106(D15), 17 375-17 401.

Volz, F. E. 1972. Infrared refractive index of atmospheric aerosol substances. Appl. Opt. 11, 755-759.

Volz, F. E. 1973. Infrared optical constants of ammonium sulfate, Sahara dust, volcanic pumice, and flyash. Appl. Opt. 12, 564-568.

Volz, F. E. 1983. Infrared optical constants of aerosols at some locations. Appl. Opt. 22, 3690-3700.

Wang, J., Liu, X., Christopher, S. A., Reid, J. S., Reid, E. and coauthors. 2003. The effect of non-sphericity on geostationary satellite retrievals of dust aerosols. Geophys. Res. Lett. 30(4), 2293, doi:10.1029/2003GL018697.

Weinzierl, B., Petzold, A., Esselborn, M., Wirth, M., Rasp, K. and coauthors. 2008. Airborne measurements of dust layer properties, particle size distribution and mixing state of Saharan dust during SAMUM 2006. Tellus 61B, doi:10.1111/j.1600-0889.2008.00392.x.

Wendisch, M. and von Hoyningen-Huene, W. 1994. Possibility of refractive index determination of atmospheric aerosol particles by groundbased solar extinction and scattering measurements. Atmos. Environ. 28(5), 785-792.

Wendisch, M., Pilewskie, P., Jäkel, E., Schmidt, S., Pommier, J. and co-authors. 2004. Airborne measurements of areal spectral surface albedo over different sea and land surfaces. J. Geophys. Res. 109, D08203, doi:10.1029/2003JD004392.

Wiegner, M., Gasteiger, J., Kandler, K., Weinzierl, B., Rasp, K. and co-authors. 2008. Numerical simulations of optical properties of Saharan dust aerosols with emphasis on lidar applications. Tellus 61B, doi:10.1111/j.1600-0889.2008.00381.x.

Wilmouth, D. M., Hanisco, T. F., Donahue, N. M. and Anderson, J. G. 1999. Fourier transform ultraviolet spectroscopy of the $A^{2} \Pi_{3 / 2}-$ $X^{2} \Pi_{3 / 2}$ transition of BrO. J. Phys. Chem. 103, 8935-8945.

Xie, Q., Zhang, H., Wan, Y., Zhang, Y. and Qiao, L. 2007. Characteristics of light scattering by smoke particles based on spheroid models. $J$. Quant. Spectrosc. Radiat. Transfer 107, 72-82.

Yang, P. and Liou, K. N. 1996. Geometric-optics-integral-equation method for light scattering by nonspherical ice crystals. Appl. Opt. 35, 6568-6582.

Yang, P., Kattawar, G. W. and Wiscombe, W. J. 2004. Effect of particle asphericity on single-scattering parameters: comparison between Platonic solids and spheres. Appl. Opt. 43(22), 4427-4435.

Yang, P., Feng, Q., Hong, G., Kattawar, G. W., Wiscombe, W. J. and co-authors. 2007. Modeling of the scattering and radiative properties of nonspherical dust-like aerosols. J. Aeros. Sci. 38, 9951014.

Yoshino, K., Freeman, D. E. and Parkinson, W. H. 1984. High resolution absorption cross section measurements of $\mathrm{N}_{2} \mathrm{O}$ at 295-299 $\mathrm{K}$ in the wavelength region 170-222 nm. Planet. Space. Sci. 32, 1219-1222.

Zuev, V. E. and Krekov, G. M. 1986. Atmospheric Optical Models. Gidrometeoizdat, Leningrad (in Russian).

Zukic, M., Torr, D. G., Spann, J. F. and Torr, M. R. 1990. Vacuum ultraviolet thin films. 1: Optical constants of $\mathrm{BaF}_{2}, \mathrm{CaF}_{2}, \mathrm{MgF}_{2}$, $\mathrm{Al}_{2} \mathrm{O}_{3}, \mathrm{HfO}_{2}$, and $\mathrm{SiO}_{2}$ thin films. Appl. Opt. 29, 4284-4292. 